\title{
Catalytic Conversion of Biomass to Fuels and Chemicals Using Ionic Liquids
}

Wei Liu

Richard Zheng

Heather Brown

Joanne Li
John Holladay

Alan Cooper

Tony Rao

March 2012

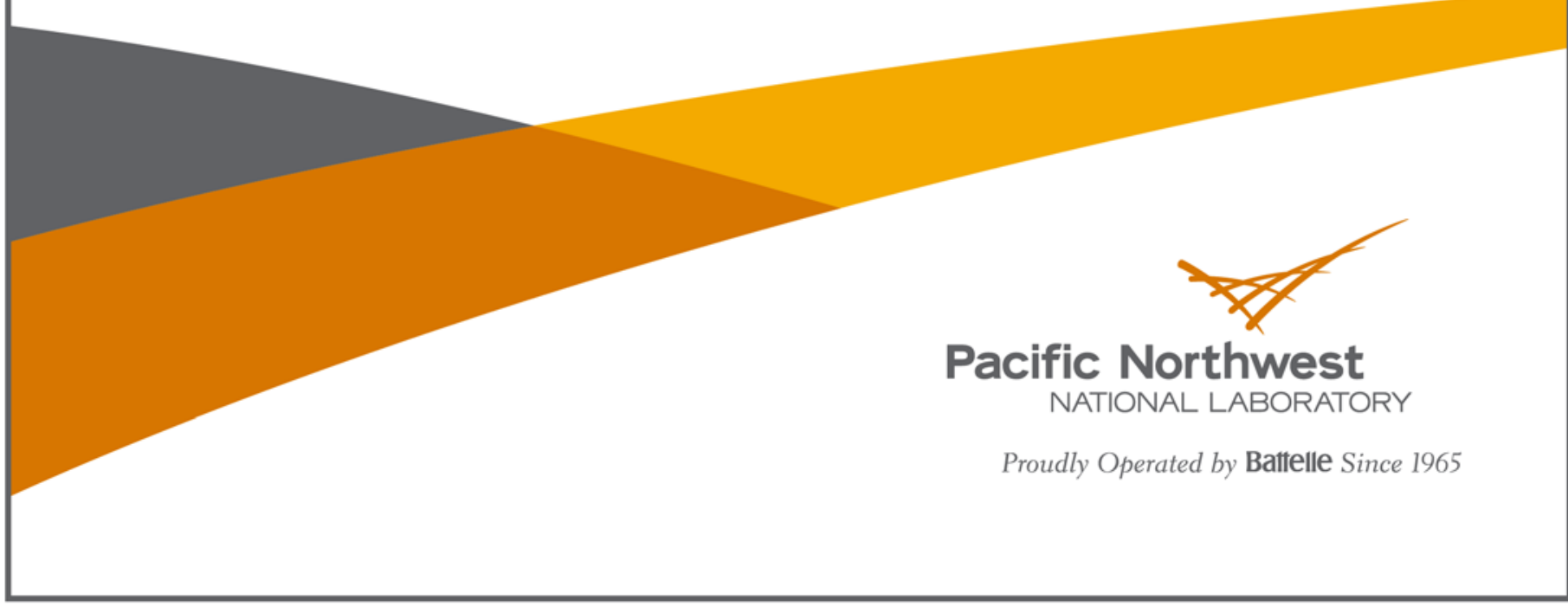




\section{DISCLAIMER}

This report was prepared as an account of work sponsored by an agency

of the United States Government. Neither the United States Government nor any agency thereof, nor Battelle Memorial Institute, nor any of their employees, makes any warranty, express or implied, or assumes any legal liability or responsibility for the accuracy, completeness, or usefulness of any information, apparatus, product, or process disclosed, or represents that its use would not infringe privately owned rights. Reference herein to any specific commercial product, process, or service by trade name, trademark, manufacturer, or otherwise does not necessarily constitute or imply its endorsement, recommendation, or favoring by the United States Government or any agency thereof, or Battelle Memorial Institute. The views and opinions of authors expressed herein do not necessarily state or reflect those of the United States Government or any agency thereof.

PACIFIC NORTHWEST NATIONAL LABORATORY

operated by

BATTELLE

for the

UNITED STATES DEPARTMENT OF ENERGY

under Contract DE-AC05-76RL01830 


\title{
Catalytic Conversion of Biomass to Fuels and Chemicals Using Ionic Liquids
}

\author{
Wei Liu John Holladay \\ Richard Zheng Allan Cooper \\ Heather Brown Tony Rao \\ Joan Li
}

March 2012

Prepared for

the U.S. Department of Energy

under Contract DE-AC05-76RL01830

Pacific Northwest National Laboratory

Richland, Washington 99352 



\begin{abstract}
This project provides critical innovations and fundamental understandings that enable development of an economically-viable process for catalytic conversion of biomass (sugar) to 5hydroxymethylfurfural (HMF). A low-cost ionic liquid (Cyphos 106) is discovered for fast conversion of fructose into HMF under moderate reaction conditions without any catalyst. HMF yield from fructose is almost $100 \%$ on the carbon molar basis. Adsorbent materials and adsorption process are invented and demonstrated for separation of 99\% pure HMF product and recovery of the ionic liquid from the reaction mixtures. The adsorbent material appears very stable in repeated adsorption/regeneration cycles. Novel membrane-coated adsorbent particles are made and demonstrated to achieve excellent adsorption separation performances at low pressure drops. This is very important for a practical adsorption process because ionic liquids are known of high viscosity. Nearly 100\% conversion (or dissolution) of cellulose in the catalytic ionic liquid into small molecules was observed. It is promising to produce HMF, sugars and other fermentable species directly from cellulose feedstock. However, several gaps were identified and could not be resolved in this project. Reaction and separation tests at larger scales are needed to minimize impacts of incidental errors on the mass balance and to show 99.9\% ionic liquid recovery. The cellulose reaction tests were troubled with poor reproducibility. Further studies on cellulose conversion in ionic liquids under better controlled conditions are necessary to delineate reaction products, dissolution kinetics, effects of mass and heat transfer in the reactor on conversion, and separation of final reaction mixtures.
\end{abstract}





\section{Summary}

This project built on earlier PNNL discoveries about catalytic conversion of sugars to HMF by using a soluble catalyst in an ionic liquid solvent (Zhao et al. 2007) and invention of adsorption separation technologies for recovery of HMF and ionic liquid from the reaction mixtures (Liu et al. 2011). The goal is to develop an economically-viable process for direct catalytic conversion of biomass to 5- HMF as a key intermediate and a flexible platform for producing chemicals and fuels. The current project effort focused on process innovations, identifying and addressing key technical barriers in reaction, separation, and feedstock areas for development of a practical ionic liquid-based catalytic process. The specific objectives laid out in the original proposal were (i) Develop a scalable, continuous flow reaction process using recycled ionic liquid; (ii) Develop a practical separation process to produce 99\%-purity HMF, and 99.9\% recovery of recycled ionic liquid; and (iii) Demonstrate the impact of different carbohydrates (fructose, glucose, mixed sugar, and cellulosic biomass) on HMF yield.

This project work is directly relevant to Objective 2(B) of the Biomass Research and Development Initiative, as laid out in U.S.C. 8606(b): “... to develop high-value biobased products as substitutes for petroleum-based feedstocks and products.” The novel approach being pursued in this project also has the potential to enable direct conversion of biomass to HMF, thereby lowering the cost enough to justify fuel production. In this way, the project also contributes to Objective 2(A) of the Biomass Research and Development Initiative: “...to develop high-value biobased products to enhance the economic viability of biobased fuels and power."

The research results are summarized under four task areas below.

Task 1 - Develop catalytic reaction process. A number of ionic liquids (and catalysts) were tested for HMF production from fructose, glucose, and high fructose corn-syrup using combinatorial chemistry and a specific low-cost ionic liquid was identified that achieved high HMF conversion from fructose without the use of catalysts. Several important parameters were further investigated and optimized. A continuous flow reactor was also successfully demonstrated, but the yields from this reactor were not nearly as good as for the batch reactor system. It is presumed that further refining and optimization of the continuous reactor would result in increased yields. Other significant accomplishments include the discovery of a 
previously unreported reaction product in significant quantities. This unknown product could be beneficial to the process if the product is identified to be of higher potential value. It was found that the unknown would be an intermediate reaction and could be converted back to HMF and fructose when it was further reacted in the ionic liquid. As a result, net conversion of fructose to HMF product was almost stoichiometric on molar basis.

Task 2 - Develop separation process. Several simulated reaction mixtures and a number of commercial adsorbents were tested with the original IL proposed and the one ultimately selected as most effective in task 1. A few promising candidates were identified. The most promising one is silicalite materials. One sample was proved stable over multiple (47) adsorption/regeneration cycles under various conditions. With the commercial silicalite powder as an adsorbent, however, only 85\% pure HMF was obtained with 12\% residual IL. The adsorption with such adsorbent powder had to be conducted at very high pressures. As a result, a novel adsorbent material was developed by PNNL researchers that, in combination with effective adsorptiondesorption process parameters achieved closer to the originally proposed purities of $99 \%$ for HMF (with 92-95\% recovery) and IL (with 98-99\% recovery). The new adsorbent material enabled the adsorption process be conducted with low pressure drops and feasible for scale up. Additional accomplishments include the development of several novel methods for highthroughput adsorbent screening techniques (an example is solid-liquid separation for multi-well reactors).

Task 3 - Evaluation of different feedstock. Cellulose and other sugars were evaluated with the original IL in batch mixing reactors at larger scale, with addition of external catalyst improving the product conversion yields. Cellulose feedstock produced as high a yield as glucose and sucrose. However, the HMF conversion yields obtained from cellulose are relatively discouraging compared to those from Task 1 (as the overall yields were much lower than those obtained for fructose). These experiments performed with cellulose were not always reproducible and hence inconclusive. Better results for cellulose could be achieved in further experimentation with improved controlled procedures and equipment.

Task 4 - Process economics analysis. The PNNL team worked with UOP (partner) and developed the required process flow chart and other inputs in order for UOP to conduct the techno-economic and LCA analysis. 


\section{Acknowledgments}

We would like to thank our colleagues at PNNL, Drs. James White, Michael Lilga, and John Lee, for helpful discussions and consulting, Dr. Al Robertson at Cytec for providing the ionic liquid samples, post and student interns, Joanne Li and Joshua Croshaw, for their assistance to some experimental work. We also would like to thank our industrial partners - UOP, Timothy Brandvold, Joseph Kocal, Sharry Lynch, for starting and working this project with us. This project was funded by USDA under Grant Agreement \# 68-3A75-7-613. 



\section{Acronyms and Abbreviations}

$\begin{array}{ll}\text { Cyphos 106: } & \text { triisobutyl(methyl)phosphonium tosylate } \\ \text { EMIN]Cl : } & \text { 1-ethyl-2-methyl imidazolium chloride } \\ \text { FDC : } & \text { 2,5-furandicarbaldehyde } \\ \text { FDCA: } & \text { 2,5-furandicarboxylic acid } \\ \text { HMF: } & \text { 5-hydroxymethylfurfural } \\ \text { PX: } & \text { para-xylene } \\ \text { PTA: } & \text { terephthalic acid }\end{array}$





\section{Contents}

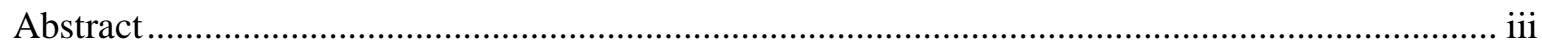

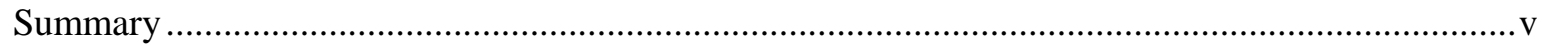

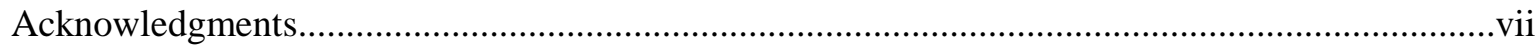

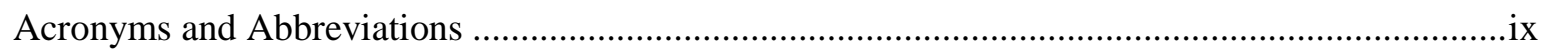

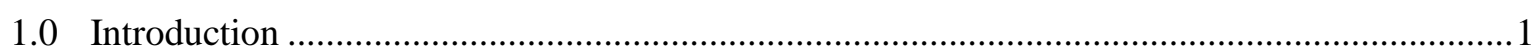

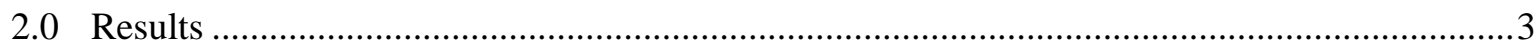

2.1 Task 1- Development of catalytic reaction process..........................................................

2.2 Task 2 - development of separation process for isolation of HMF production and

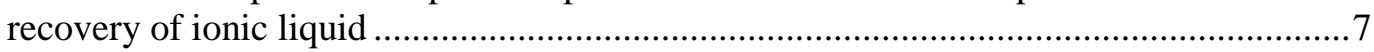

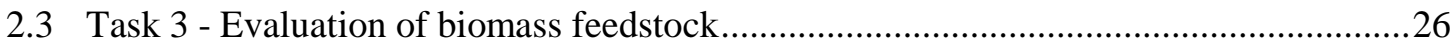

2.4 Task 4 - Technical and economic analysis for scale-up .................................................29

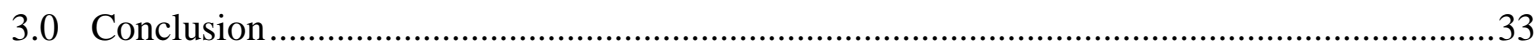

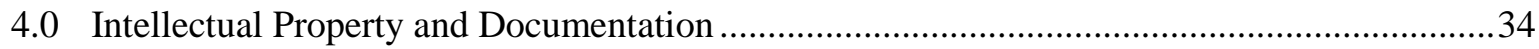

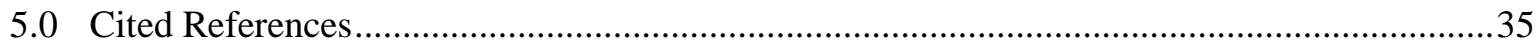




\section{Figures}

Figure 1. Variations of fructose and HMF content in Cyphos 106 ionic liquid reaction mixture with reaction time at different temperatures (about $10 \mathrm{wt} \%$ fructose loading).

Figure 2. Comparison of batch adsorption results of zeolite materials with two different ionic liquids ( $1 \mathrm{~h}$ adsorption time at $60^{\circ} \mathrm{C}$; Feed: $8 \mathrm{wt} \% \mathrm{HMF}, 0.5 \mathrm{wt} \%$ glucose ionic liquid/water solutions)

Figure 3. Characteristic adsorption and regeneration profiles of a column packed with mesosilicalite powder.

Figure 4. Stability of adsorbent material over 47 adsorption/regeneration cycles.

Figure 5. Adsorption and regeneration profiles at $50^{\circ} \mathrm{C}$ of the organic-philic adsorbent column (Ionic liquid \#2 reaction mixture; FRU = fructose, UNK = by product; IL = ionic liquid, $\mathrm{HMF}$ purity $=\mathrm{HMF} /(\mathrm{HMF}+\mathrm{FRU}+\mathrm{UNK}+\mathrm{IL}))$

Figure 6. Adsorption and regeneration profiles at $50^{\circ} \mathrm{C}$ of the nano-silicalite adsorbent column (Ionic liquid \#2 reaction mixture; FRU = fructose, UNK = by product; IL = ionic liquid, HMF purity = HMF/(HMF+FRU+UNK+IL)).

Figure 7. Schematic of experimental apparatus for super critical $\mathrm{CO}_{2}$ extraction of $\mathrm{HMF}$ from ionic liquid.

Figure 8. Typical adsorption breakthrough curves with an ionic liquid reaction mixture (Column\#13, $50^{\circ} \mathrm{C}, 0.944 \mathrm{cc} / \mathrm{min}$ of feed rate).

Figure 9. Typical regeneration profiles (Column\#13, $50^{\circ} \mathrm{C}, 2.0 \mathrm{cc} / \mathrm{min}, 60$-min water flushing followed by 60 -min methanol flushing).

Figure 10. Dried product and by-product samples isolated from different steps of an adsorption/regeneration cycle (Column \#13)

Figure 11. Membrane-coated adsorbent particle

Figure 12. Adsorption separation performances of a column packed with silicalite membranecoated silicalite particles (Column $\# 19$, at $50^{\circ} \mathrm{C}$ ) with a fructose ionic liquid reaction mixture.

Figure 13. Adsorption separation performances of a column packed with silicalite membranecoated silicalite particles (Column $\# 19$, at $50^{\circ} \mathrm{C}$ ) with a cellulose ionic liquid reaction mixture (\#1 extracted batch soln from Run\# 60763-79-1).

Figure 14. Process flow diagram for an ionic liquid catalytic process for conversion of fructose into $\mathrm{HMF}$

Figure 15. Conversion of fructose and unknown with recycled ionic liquid. 


\section{Tables}

Table 1. Parameters screened in combinatorial chemistry tests....................................................4

Table 2. Batch reactor testing results and carbon balance (fructose was added into the ionic liquid solution under continuous stirring in $\mathrm{N}_{2}$ gas blanket). .........................................................

Table 3. Reaction testing results of fructose/Cyphos 106 in a counter-current flow reactor

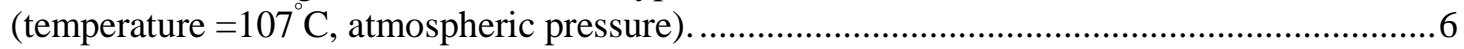

Table 4. Parameters screened in combinatorial adsorption tests...................................................8

Table 5. Adsorbent column tests with three different silicalite-type materials (about 5 wt\% HMF and $2.5 \mathrm{wt} \%$ fructose in a reaction mixture of the ionic liquid \#2)......................................11

Table 6. Compositions of HMF product recovered from regeneration effluent with the meso-

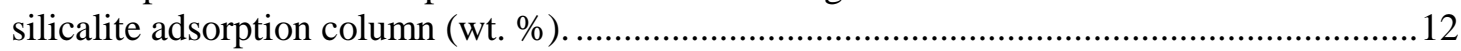

Table 7.Adsorbent columns evaluated for separation of high purity HMF. ....................................15

Table 8. Mass balances of adsorption/regeneration cycle (Column \#13). ......................................19

Table 9.Total mass balances of adsorption/regeneration cycle (Column\#13, Cycle 6)...................19

Table 10.Membrane-coated adsorbent particles prepared and tested this period.............................22

Table 11.Conversion of cellulose in a $\mathrm{CuCl}_{2}-\mathrm{CrCl}_{2} /[\mathrm{EMIN}] \mathrm{Cl}$ catalyst/ionic system....................28

Table 12.Sizes of main equipment for proposed process flow diagram. ......................................32 



\subsection{Introduction}

There has been an interest in 5-hydroxymethylfurfural (HMF) as a reaction intermediate since the 1890's because of its potential application to a wide variety of desirable end products. A comprehensive review of synthesis chemistry of HMF and its derivatives was provided by Kunz (1993) and Lewkowski (2001). HMF and its furan derivatives are considered as a suitable starting material for production of various thermo-resistant polymers and complex macrocycles. HMF can be converted into 2,5-furandicarbaldehyde (FDC) and 2,5-furandicarboxylic acid (FDCA) by selective oxidation, which can be used as a polymer monomer. Selective reduction of HMF can lead to products such as 2,5-hydroxymethylfuran and 2,5-

bis(hydroxymethyl)tetrahydrofuran, which can be used as alcohol components in the production of polyester. These molecules can become building blocks for numerous polyesters and polyamides (Bicker et al. 2003). Thus, a new chemical and polymer industry may be developed completely based on biomass-derived products (Werpy \& Petersen 2004). Furthermore, diesel fuel additives can be prepared by reacting HMF with organic acids or alcohols to form esters or ethers (Gruter \& Dautzenberg 2007). Over 1000 papers have been published concerning HMF synthesis and applications. A variety of catalysts (including organic acids, inorganic acids, salts, Lewis acids, ion-exchange resins and zeolite) and solvents (aqueous, organic, mixed aqueous/organic) have been tried.

The primary barrier to using HMF in high-volume chemical and fuel applications is its high cost and correspondingly low availability. To be commercially viable, HMF must be produced on a large scale at a cost comparable to petroleum-derived feedstock such as paraxylene (PX) and terephthalic acid (PTA). Fructose or glucose molecule can be converted into HMF by loss of three water molecules, while sugars can be produced economically through various processes. Production of HMF from sugar feedstock appears to be a very attractive process route from points of views of reaction stoichiometry and raw material supply. However, the actual conversion chemistry could be complex and a series of side-reactions may occur under reaction conditions, which strongly affect the process efficiency. As a result, HMF yield and/or selectivity reported in earlier literatures were often low. 
More efficient and scalable catalytic conversion processes have been sought. An organic/aqueous two-phase reactor system was reported by Roman-Leshkov et al. (2006) for conversion of D-fructose to HMF. In the two-phase system, HMF product is extracted into the organic solvent phase while reactions occur in the aqueous phase. The authors reported $80 \%$ HMF selectivity at $90 \%$ fructose conversion, i.e., $72 \%$ HMF yield, under optimum reaction conditions. However, HMF solubility in the organic solvent is low and the two-phase reaction involves a complex process. Ionic liquids (IL) are a new solvent medium for catalytic conversion of HMF. Simple sugars, cellulose and even whole biomass are soluble in highly ionic media (Fukaya, et al. 2006). Conversion of fructose to HMF in ionic liquids was reported by Moreau et al. (2006). Using an ionic liquid in combination with a soluble catalyst, Zhao et al. (2007) discovered that both glucose and fructose can be converted into HMF with little formation of byproducts. Therefore, HMF comprises $99 \%$ of the product in the water extract of the reacted mixture, which is very beneficial to sugar utilization and HMF product separation. HMF production in ionic liquids has become an active catalysis research subject area since then.

In this work, we attempt to address some fundamental issues related to practical development of an ionic liquid catalytic process for HMF production, such as determination of ionic liquids that are both effective and low-cost, reaction kinetics and impacts of important process parameters on reaction performances, effective separation of pure HMF product, recovery of used ionic liquid, impacts of different feedstock on product distribution and HMF yield, and carbon balance.

Research results are summarized under four tasks described in the following sections. 


\subsection{Results}

\subsection{Task 1- Development of catalytic reaction process}

The scope of work conducted under this task included (i) batch reactor testing of [EMIN]Cl-based reactions, (ii) combinatorial screening tests of new ionic liquid+ catalyst combinations with fructose, and syrup, and glucose as a feed, (iii) systematic tests of fructose + Cyphos 106 reaction system in a batch reactor, and (iv) reaction testing of the fructose + Cyphos 106 in a counter-current flow reactor.

Catalysis chemistry screening tests. Two series of combinatorial chemistry tests were performed to screen different ionic liquid + catalyst combinations and identify the most promising one for reaction process development. The tests were carried out on the high throughput combinatorial apparatus at PNNL. A small volume of ionic liquids (about 0.5cc) was used in the screening tests. The experimental matrix is summarized in table 1 . The testing results with 1-ethyl-2-methyl imidazolium chloride ([EMIN]Cl) ionic liquid are consistent with previous studies (1), and catalyst addition is necessary to obtain appreciable sugar conversion and high HMF yield. However, this ionic liquid was too expensive to use at a larger quantity and its melting temperature (about $80^{\circ} \mathrm{C}$ ) is relatively high. Thus, six other ionic liquids of different properties were obtained from different vendors. One promising ionic liquid was found that provide higher activity and better HMF yield even without any catalyst additive than the previous [EMIN]Cl. More importantly, this ionic liquid with a brand name as Cyphos 106 can be obtained from a commercial supplier at a significantly lower cost than [EMIN]Cl, and prospect of industrial-scale production has been confirmed with the supplier. This discovery was crucial to the process research and development activities that required a much larger quantity of the ionic liquid (a few kilograms in the current laboratory scale) than what was used in the screening tests (tens of grams). An invention disclosure was filed for the new ionic liquid system (2). Since the ionic liquid is the most expensive material, decreasing its cost is vital to process economics. 
Table 1. Parameters screened in combinatorial chemistry tests.

\begin{tabular}{|l|l|l|}
\hline & $1^{\text {st }}$ series & $2^{\text {nd }}$ series \\
\hline Ionic liquid & $\begin{array}{l}\text { EMIM]Cl -used in previous studies } \\
(1)\end{array}$ & $\begin{array}{l}\text { Six different ionic liquids of lower } \\
\text { cost }\end{array}$ \\
\hline Feedstock & $\begin{array}{l}\text { Fructose, high fructose corn syrup, } \\
\text { D-glucose }\end{array}$ & $\begin{array}{l}\text { Fructose, high fructose corn syrup, } \\
\text { D-glucose }\end{array}$ \\
\hline Catalyst & None, $\mathrm{AlCl}_{3}, \mathrm{H}_{2} \mathrm{SO}_{4}, \mathrm{CrCl}_{2}$ & None, $\mathrm{H}_{2} \mathrm{SO}_{4}, \mathrm{AlCl}_{3}, \mathrm{CuCl}_{2}, \mathrm{CrCl}_{2}$ \\
\hline Temperature & $85^{\circ} \mathrm{C}, 120^{\circ} \mathrm{C}$ & $85^{\circ} \mathrm{C}, 100^{\circ} \mathrm{C}$ \\
\hline
\end{tabular}

Reaction kinetic tests in a batch reactor. A batch reactor apparatus was built with continuous inert gas purge and stirring. A number of kinetics tests were conducted by measuring variation of batch compositions with reaction time. Relative ranking of different reaction systems by the combinatorial screening tests ( $\sim .5 \mathrm{cc}$ volume) was validated by the batch reactor testing at a much large volume ( 50cc). Typical results are illustrated in Figure 1. Fructose conversion in the ionic liquid was fairly rapid even without any catalyst addition. $90 \%$ of fructose in the ionic liquid disappeared in about $10 \mathrm{~min}$ at $80^{\circ} \mathrm{C}$ of reaction temperature. $99 \%$ of fructose conversion can be obtained at a higher temperature or longer reaction time. HMF is the dominant reaction product. The common byproducts, levunlinic acid and formic acid, were not detected within our analytical limit. From the overall carbon balance, HMF yield from fructose can be as high as $>80 \%$.
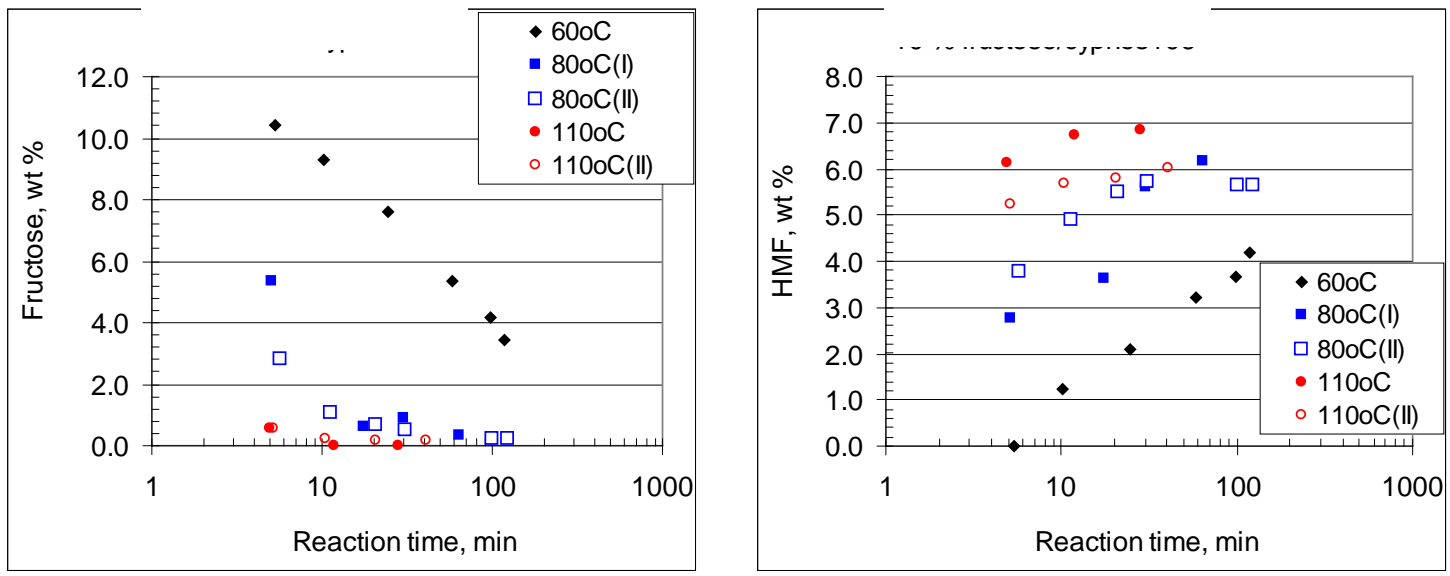

Figure 1. Variations of fructose and HMF content in Cyphos 106 ionic liquid reaction mixture with reaction time at different temperatures (about $10 \mathrm{wt} \%$ fructose loading).

A series of experiments were performed in a batch reactor to examine impacts of fructose loading, moisture content, reaction temperature, and reaction time on the product distribution 
with the new ionic liquid. Fructose conversion itself showed fast kinetics. The byproduct species derived from fructose were detected by high pressure liquid chromatography (HPLC) analysis but could not be identified because they do not match with the existing calibration compounds. No literature reference has been found about molecular identity of these intermediates either. Thus, they are lumped as "unknown” species in this report. Initial LC/MS characterization suggests they could be partially dehydrated sugar molecules. If we assume the unknown have the same HPLC response factor as fructose, carbon balances of a few batch reactor tests are listed in Table 2. The overall carbon balance between the final reacted product mixture and feed fructose is close to $100 \%$. On carbon number basis, fructose conversion easily reaches $98 \sim 99 \%$, HMF is the dominant product, and yield of the unknown is a significant number. The unknown yield generally increases with initial fructose loading in the reactor batch.

Table 2. Batch reactor testing results and carbon balance (fructose was added into the ionic liquid solution under continuous stirring in $\mathrm{N}_{2}$ gas blanket).

\begin{tabular}{|c|c|c|c|c|c|c|c|c|}
\hline \multirow[b]{2}{*}{ Batch \# } & \multicolumn{4}{|c|}{ Reaction conditions } & \multicolumn{4}{|c|}{ Carbon balance, atomic \% } \\
\hline & $\begin{array}{l}\text { Temp, } \\
{ }^{\circ} \mathrm{C}\end{array}$ & $\begin{array}{l}\text { Time, } \\
\text { min }\end{array}$ & $\begin{array}{l}\text { Purge } \\
\text { gas, } \\
\text { sccm }\end{array}$ & $\begin{array}{l}\text { Fructose } \\
\text { loading, } \\
\text { wt\% }\end{array}$ & $\begin{array}{l}\text { Out/in } \\
\text { (\%) }\end{array}$ & $\begin{array}{l}\text { Fructose } \\
\text { Conversion } \\
(\%)\end{array}$ & $\begin{array}{l}\text { HMF } \\
\text { yield } \\
\text { (\%) }\end{array}$ & $\begin{array}{l}\text { Unknown } \\
\text { yield (\%) }\end{array}$ \\
\hline \#8 & 110 & 20 & 50 & 9.5 & 97.7 & 99.1 & 83.3 & 13.1 \\
\hline \#9 & 110 & 20 & 50 & 24.7 & 103.3 & 98.5 & 74.0 & 26.0 \\
\hline$\# 10$ & 85 & 20 & 50 & 10.6 & 101.8 & 98.4 & 77.4 & 22.5 \\
\hline$\# 11$ & 110 & 10 & 50 & 10.1 & 100.5 & 97.9 & 78.7 & 19.4 \\
\hline
\end{tabular}

Reaction testing results in a counter-current flow reactor. A flow reactor testing system was set up. Continuous feeding of sugar powder and viscous ionic liquid at small flow rates $(0.1-1.0 \mathrm{cc} / \mathrm{min})$ turned out to be difficult. The ionic liquid is in a solid phase at room temperature. The heat-traced feed line was readily plugged if there was a cold spot. The sugar powder is very sensitive to moisture and the powder conveying device often got mal-functioned when the powder got sticky. Thus, sugar and ionic liquid were dissolved into de-ionized water to turn into a respective solution at room temperature. Then, the sugar and ionic liquid solution were delivered by two liquid pumps, respectively. The sugar solution and ionic liquid solution were combined into one liquid feed line. The mixed solution was fed into a flash drum that was 
heated at temperatures above $100^{\circ} \mathrm{C}$. It was expected in the flash drum that the water was vaporized, and sugar and ionic liquid were turned into a liquid fluid. The sugar/ionic liquid flowed from the drum into a reactor tube by gravity, while the water vapor was swept away by $\mathrm{N}_{2}$ gas coming up from the reactor tube. The $\mathrm{N}_{2}$ lift gas was introduced at the bottom of the reactor tube. As a result, the sugar/ionic liquid fluid moved downwards along the reactor tube as the N2 gas moved up. As a result, a counter-current flow pattern was generated. The reactor tube temperature was controlled by a three-zone temperature controller to achieve a uniform temperature profile along the reactor length.

Table 3 lists the testing results under one set of constant reaction conditions. The residence time of the sugar/ionic liquid mixture inside the reactor tube is estimated fairly short (in minutes) due to short reactor tube and free falling of the liquid. The content of the unknown species in the reacted product mixture was fairly significant, while presence of levulinic acid and formic acid was beyond the HPLC detection. The flow reactor testing results are consistent with the finding from the batch reactor testing. Formation of unknown appears to follow a different reaction path from HMF production, and the unknown formation rate is faster than HMF production.

Table 3. Reaction testing results of fructose/Cyphos 106 in a counter-current flow reactor (temperature $=107^{\circ} \mathrm{C}$, atmospheric pressure).

\begin{tabular}{|l|l|l|l|l|l|l|l|l|l|l|l|}
\hline \multicolumn{2}{|l|}{$\begin{array}{l}\text { Stream } \\
\text { time }\end{array}$} & \multicolumn{2}{l|}{ Feed, cc/min } & $\begin{array}{l}\text { Mass bal, } \\
\text { wt\% }\end{array}$ & \multicolumn{6}{l|}{ Product composition, wt\% } \\
\hline min & $\#$ & $\begin{array}{l}\text { Sugar } \\
\text { soln }\end{array}$ & $\begin{array}{l}\text { IL } \\
\text { soln }\end{array}$ & $\begin{array}{l}\text { Out/in } \\
(\%)\end{array}$ & IL & Unk & Fru & Glu & LA & FA & HMF \\
\hline 91 & 5 & 0.24 & 0.98 & 98 & 91.6 & 4.6 & 3.9 & 0.2 & 0.0 & 0.0 & 4.4 \\
\hline 116 & 6 & 0.25 & 0.99 & 99 & 91.0 & 4.7 & 4.4 & 0.2 & 0.0 & 0.0 & 4.2 \\
\hline 129 & 7 & 0.25 & 0.98 & 100 & 91.7 & 6.3 & 4.6 & 0.2 & 0.0 & 0.0 & 4.2 \\
\hline
\end{tabular}

Unk = reaction intermediates; Fru = fructose; Glu = Glucose; LA= Levulinic Acid; FA= Formic Acid

The major learning and accomplishments in this task are summarized as follows:

- Cyphos 106 is discovered as an effective, low-cost ionic liquid for conversion of fructose into HMF first time.

- Conversion of fructose in this ionic liquid occurs under moderate conditions without any catalyst addition: 2 to $60 \mathrm{~min}, 80$ to $110^{\circ} \mathrm{C}$, atmospheric pressure. 
- Formation of byproduct acids is negligible.

- However, some unidentified species (unknown) are found present in the reacted mixture and could not be determined by current HPLC methods. These species are likely to be present in the other reaction systems in the literature, which may not be noticed or reported.

- Formation of the unknown could be not eliminated by adjusting reaction conditions, which likely occurs concomitantly with dissolution of sugar molecules. This could be an interesting research subject for fundamental catalysis studies.

- Conversion of glucose into HMF requires addition of $\mathrm{CrCl}_{2}$ catalysts.

\subsection{Task 2 - development of separation process for isolation of HMF production and recovery of ionic liquid}

The major activities conducted under this task were 1) screening of adsorbent materials with combinatorial chemistry technique, 2) adsorption testing of small columns packed with adsorbent powder, 3) HMF product isolation and ionic liquid recovery, 4) preparation of engineered adsorbent particles, and 5) adsorption performances of columns packed with engineered particles

Screening of adsorbent materials. About 24 of solid adsorbent materials were evaluated for selective adsorption of HMF using PNNL's combo-apparatus. Simulated liquid mixtures prepared with [EMIN]Cl and Cyphos 106 ionic liquids were used. All the adsorbents and feed compositions were tested under same adsorption conditions. The adsorption capacity and selectivity were deduced by analyzing the liquid composition before and after adsorption. The experimental matrix is listed in Table 4. A large number of adsorbent + feed combinations were generated from this experimental matrix. Several combinatorial batch runs were performed. Regeneration of the saturated adsorbents was also tested. Several promising adsorbent materials were identified that provide $>20 \mathrm{wt} \%$ HMF adsorption capacity. 
Table 4. Parameters screened in combinatorial adsorption tests.

\begin{tabular}{|l|l|l|}
\hline Adsorbent & $\begin{array}{l}\text { Simulated mixture with [EMIM]Cl } \\
\text { ionic liquid (\#1) }\end{array}$ & $\begin{array}{l}\text { Simulated mixture with } \\
\text { Cyphos 106 ionic liquid (\#2) }\end{array}$ \\
\hline$\bullet$ Zeolite series (Z) & $\bullet$ Feed A: 1\% Glucose / 0.5\% & $\bullet$ Feed A: 7.3\% HMF, 12.7\% \\
• Carbon series (C) & Levulinic acid / 3.5\% HMF / 95\% & $\mathrm{H}_{2} \mathrm{O}, 80 \%$ ionic liquid. \\
• Silica series (S) & ionic liquid. & Feed B: 0.5\% glucose, \\
• Polymeric resin & - Feed B: 1\% Fructose / 0.5\% & 19.4\% $\mathrm{H}_{2} \mathrm{O}, 80 \%$ ionic \\
series(R) & Levulinic acid / 3.5\% HMF / 95\% & liquid. \\
& ionic liquid. & \\
& Feed C: 0.5\% Fructose / 0.25\% & \\
& Levulinic acid / 1.75\% HMF / 50\% & \\
& water / ionic liquid. & \\
\hline
\end{tabular}

Effectiveness of zeolite materials for HMF adsorption from ionic liquid mixtures is confirmed. Based on previous adsorbent screening tests, several zeolite materials were chosen for further studies. These materials all in powder form were prepared in house or obtained from the commercial sources. The adsorption was conducted by dispersing the powder into an ionic liquid/water solution mixture under continuous mixing. Two ionic liquids of different molecular structures and melting points were used to validate effectiveness of the zeolite adsorbent for selective HMF adsorption in a broad scale of ionic liquids. HMF adsorption capacity and HMF/glucose selectivity factor for the ionic liquid \#1 of higher melting point are compared to the numbers obtained with the same material for the ionic liquid \#2 of lower melting point in Figure 2. The Y-type, ZSM-5, and silicalite material all provide selective HMF adsorption over glucose with an adsorption capacity more than $10 \mathrm{wt} \%$ for both kinds of the ionic liquid mixture. The adsorption performances of the Y-type zeolite are a strong function of the metal cation. The HMF/glucose selectivity for the ionic liquid \#1 is consistently higher than that for the ionic liquid \#2. Thus, specific zeolite composition and structures need to be optimized for a given ionic liquid mixture. 


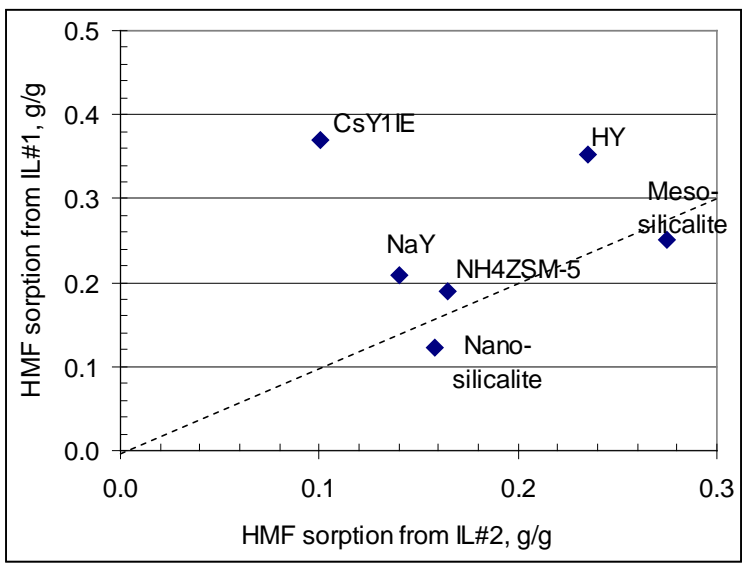

(a) Adsorption loading, g-HMF/g-dry adsorbent

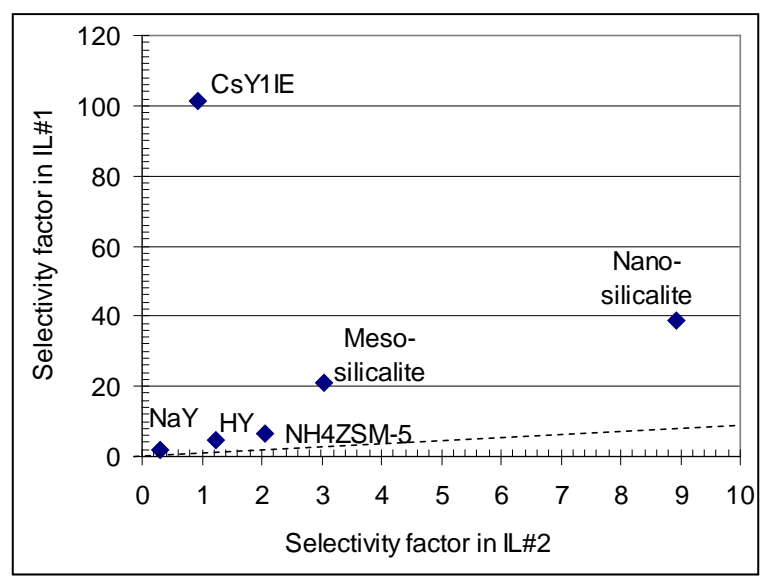

(b) HMF/glucose separation factor

Figure 2. Comparison of batch adsorption results of zeolite materials with two different ionic liquids (1 h adsorption time at $60^{\circ} \mathrm{C}$; Feed: $8 \mathrm{wt} \% \mathrm{HMF}, 0.5 \mathrm{wt} \%$ glucose ionic liquid/water solutions).

Adsorption separation tests with columns loaded with zeolite powder. Promising zeolite adsorbent materials identified from the high throughput combinatorial tests were packed into a stainless steel column in powder form. The column was tested with various simulated ionic liquid mixtures and actual reaction product mixtures at different temperatures. Figure 3a shows representative adsorption breakthrough curves of HMF, fructose (FRU), and un-identified specie (UNK). The ionic liquid mixture was introduced into the adsorption column after the residual solution in the line and detector was washed with de-ionized water. Fructose and unknown species quickly came out of the column and reached a plateau. HMF breakthrough occurred about 20min late. Selective HMF adsorption over fructose and unknown was clearly shown. After the adsorbent column was saturated, various regeneration methods were evaluated to recover HMF and rejuvenate the adsorbent.

Regeneration profiles are illustrated by Figure 3b. Residual feed solution inside the column was first washed out by use of de-ionized water within $18 \mathrm{~min}$. Then, a solvent was used to release the adsorbed HMF. The solvent elution resulted in a solution mixture mostly comprising HMF. HMF can be recovered by vaporizing the solvent. 

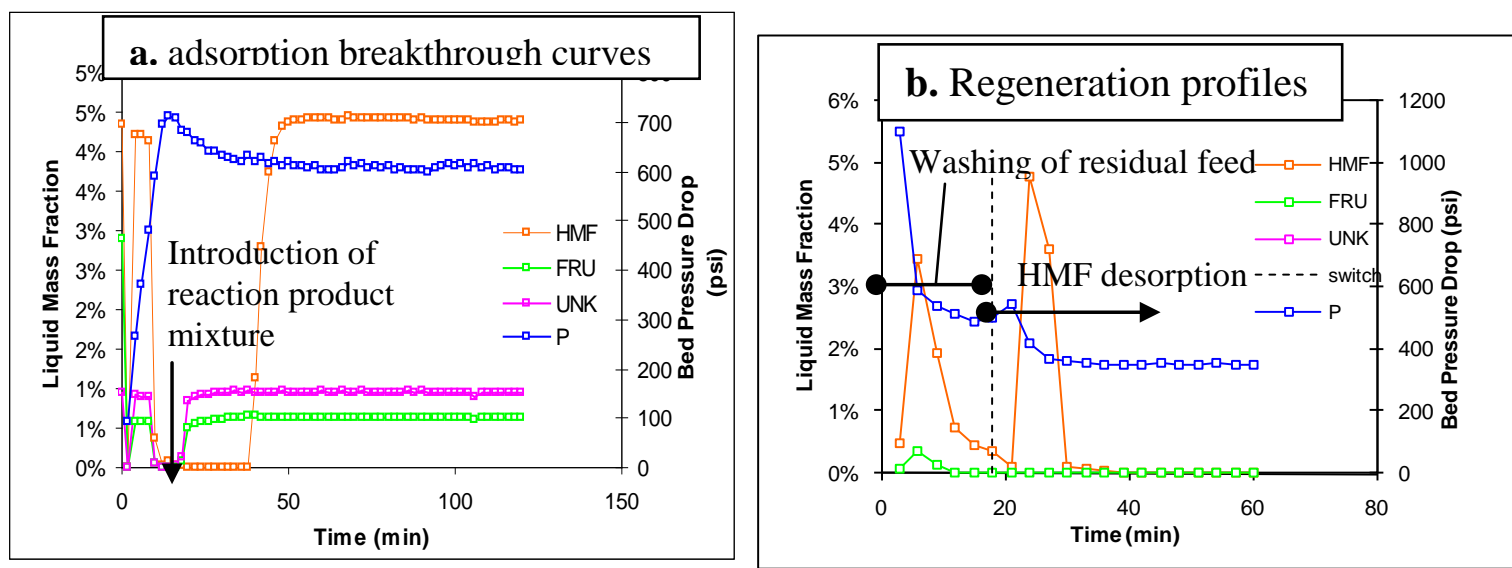

Figure 3. Characteristic adsorption and regeneration profiles of a column packed with meso-silicalite powder.

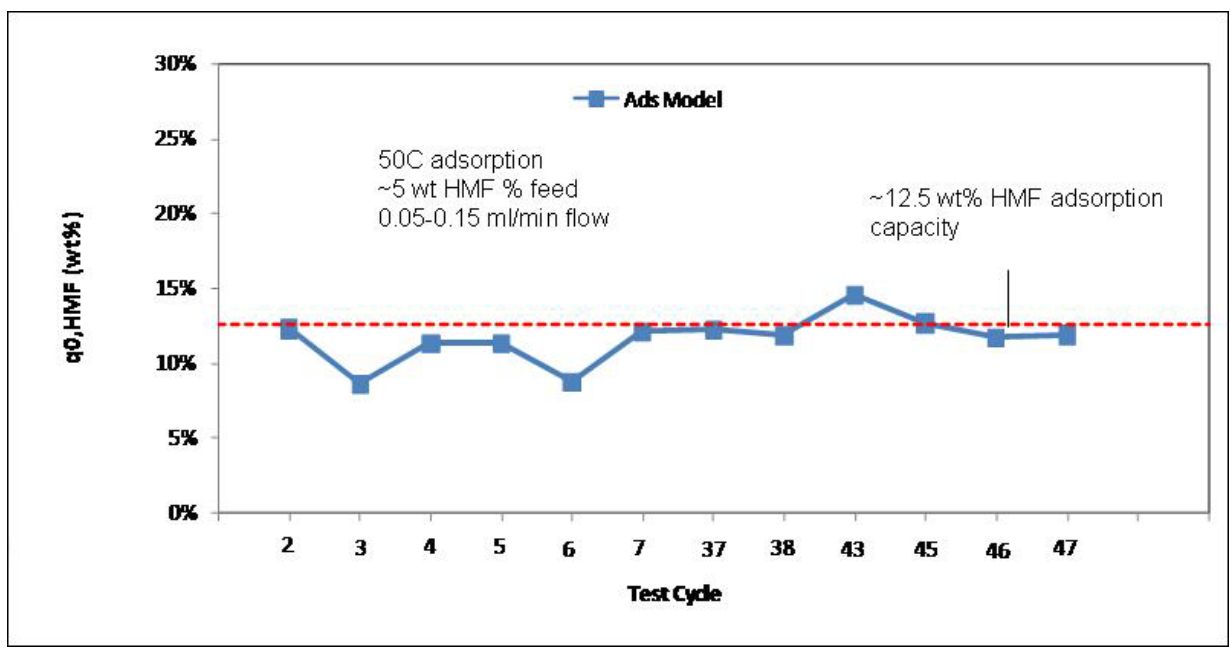

Figure 4. Stability of adsorbent material over 47 adsorption/regeneration cycles.

The same adsorbent column was tested with 47 cycles of adsorption and regeneration during a 2-month period. Different feed compositions and adsorption conditions were evaluated and different regeneration procedures and conditions were tested. The adsorbent appeared to be fairly rugged. A simple adsorption model was used to calculate the adsorption capacity from measured adsorption breakthrough curves. As shown in Figure 4, the HMF adsorption capacity appeared to be stabilized around $12.5 \mathrm{wt} \%$ under the normalized adsorption conditions. The regeneration method was effective to restore the adsorbent activity. 
Adsorption performances of a column packed with different silicalite powder. Three columns packed with different silicalite adsorbents were tested for adsorption/regeneration to recover high purity HMF. The silicalite adsorbent was selected for the packed column tests due to its excellent chemical and thermal stability and simple composition. The ionic liquid \#2 was used for the column tests due to its lower melting point and availability in a large quantity at low costs. Basic information for the column tests is summarized in Table 5. The HMF adsorption capacity was calculated from the adsorption breakthrough curve with an ionic liquid reaction mixture. The nano-silicalite prepared in house showed a higher HMF adsorption capacity based on either the adsorbent weight or the packed bed volume than the meso-porous silicalite and organic-philic zeolite. The adsorption capacity for the meso-porous silicalite was slightly affected by the adsorption temperature.

Table 5. Adsorbent column tests with three different silicalite-type materials (about 5 wt $\%$ HMF and 2.5 wt $\%$ fructose in a reaction mixture of the ionic liquid \#2).

\begin{tabular}{|l|l|l|l|l|}
\hline Run \# of packed column & Meso-40 & Meso-35 & OP-12 & Nano-5 \\
\hline Adsorbent material & $\begin{array}{l}\text { Meso- } \\
\text { porous } \\
\text { silicalite }\end{array}$ & same & $\begin{array}{l}\text { Organo- } \\
\text { philic } \\
\text { zeolite }\end{array}$ & $\begin{array}{l}\text { Nano- } \\
\text { silicalite }\end{array}$ \\
\hline Source & In-house & same & Aldrich & In-house \\
\hline Bed packing density, g/ml & 0.54 & same & 0.66 & 1.13 \\
\hline Adsorption bed temperature, ${ }^{\circ} \mathrm{C}$ & 70 & 50 & 50 & 50 \\
\hline $\begin{array}{l}\text { Adsorption capacity, g-HMF/g- } \\
\text { adsorbent }\end{array}$ & $10.6 \%$ & $11.7 \%$ & $6.8 \%$ & $12.9 \%$ \\
\hline Adsorption capacity, g-HMF/ml-bed & 0.057 & 0.063 & 0.045 & 0.146 \\
\hline
\end{tabular}

Recovery of HMF product from the regeneration effluent was attempted with the mesosilicalite packed column. The HMF-rich effluent was collected during regeneration by methanol washing. Methanol was removed by vaporization of the collected regeneration solution to obtain HMF product. Table 6 lists compositions of the recovered HMF product in comparison to the compositions of the feed and regeneration effluent stream. It can be seen that the ionic liquid is the main impurity in the final HMF product. The mass balance for HMF and ionic liquid between the adsorption and regeneration was $98.3 \%$ and $99.4 \mathrm{wt} \%$, respectively. 
Table 6. Compositions of HMF product recovered from regeneration effluent with the meso-silicalite adsorption column (wt. \%).

\begin{tabular}{|l|l|l|l|l|l|l|l|l|}
\hline Stream & HMF & IL\#2 & glucose & fructose & $\begin{array}{l}\text { formic } \\
\text { acid }\end{array}$ & $\begin{array}{l}\text { levulinic } \\
\text { acid }\end{array}$ & $\begin{array}{l}\text { By } \\
\text { product }\end{array}$ & Bal \\
\hline Feed mixture & $4.8 \%$ & $46.2 \%$ & $0.4 \%$ & $2.6 \%$ & $0.1 \%$ & $0.0 \%$ & $0.0 \%$ & $\mathrm{H}_{2} \mathrm{O}$ \\
\hline MeOH purge & $2.7 \%$ & $0.2 \%$ & $0.0 \%$ & $0.0 \%$ & $0.0 \%$ & $0.0 \%$ & $0.0 \%$ & $\mathrm{MeOH}$ \\
\hline $\begin{array}{l}\text { Isolated } \\
\text { HMF product }\end{array}$ & $\begin{array}{l}85.2 \\
\%\end{array}$ & $12.2 \%$ & $0.0 \%$ & $0.7 \%$ & $0.0 \%$ & $1.3 \%$ & $0.6 \%$ & none \\
\hline
\end{tabular}

The representative adsorption and regeneration profiles for the organic-philic adsorbent column are shown in Figure 5. Clear separation of HMF from fructose in a reaction product mixture is shown by the adsorption breakthrough curve. During regeneration, the reaction mixture trapped in the void space of the column was first flushed out by water, and then, methanol was used to regenerate the adsorbed HMF. However, some residual ionic liquid was evident during the methanol washing. As a result, the highest HMF purity among the portions collected at different elution times is about $90 \mathrm{wt} \%$.

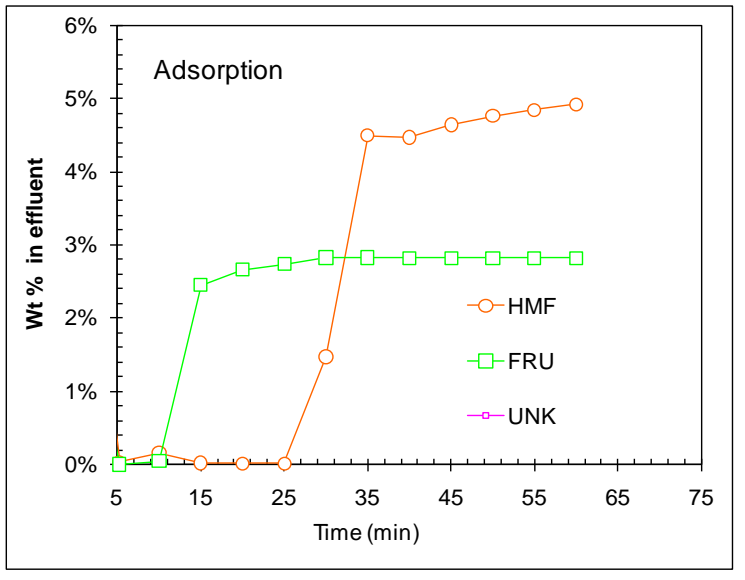

(a) Adsorption curves with a reaction mixture

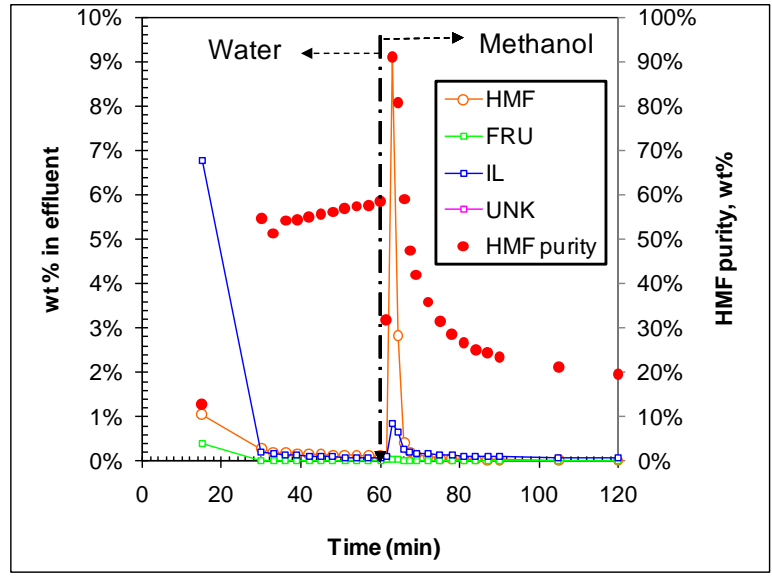

(b) Regeneration profile with water and $\mathrm{MeOH}$

Figure 5. Adsorption and regeneration profiles at $50^{\circ} \mathrm{C}$ of the organic-philic adsorbent column (Ionic liquid \#2 reaction mixture; FRU = fructose, $\mathrm{UNK}$ = by product; $\mathrm{IL}$ = ionic liquid, HMF purity $=\mathrm{HMF} /(\mathrm{HMF}+\mathrm{FRU}+\mathrm{UNK}+\mathrm{IL}))$.

Figure 6 shows representative adsorption and regeneration profiles for the nano-silicalite adsorbent column. The pressure drop through this adsorbent bed was much higher than the other two columns because of the denser packing and smaller zeolite crystals. A slow liquid flow rate 
was used during adsorption breakthrough measurements. The slower flow rate and higher capacity resulted in a longer breakthrough time than the other two columns. Compared to the regeneration profiles for the previous two columns, the ionic liquid trapped among inter-particle voids was rapidly washed out by water. The HMF purity in many portions of the collected regeneration effluent is about $96-97 \%$. It appears that the reaction by product (UNK) has strong adsorption in the zeolite, which was desorbed by methanol washing.

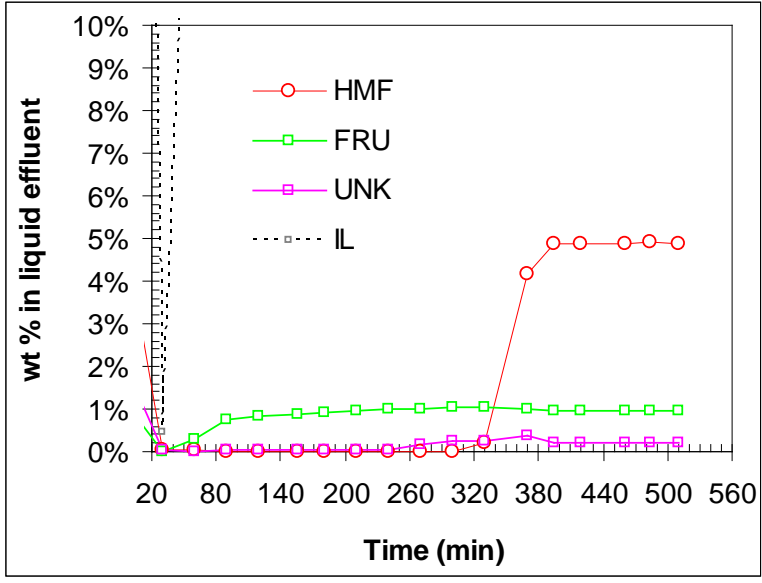

(a) Adsorption curves with a reaction mixture

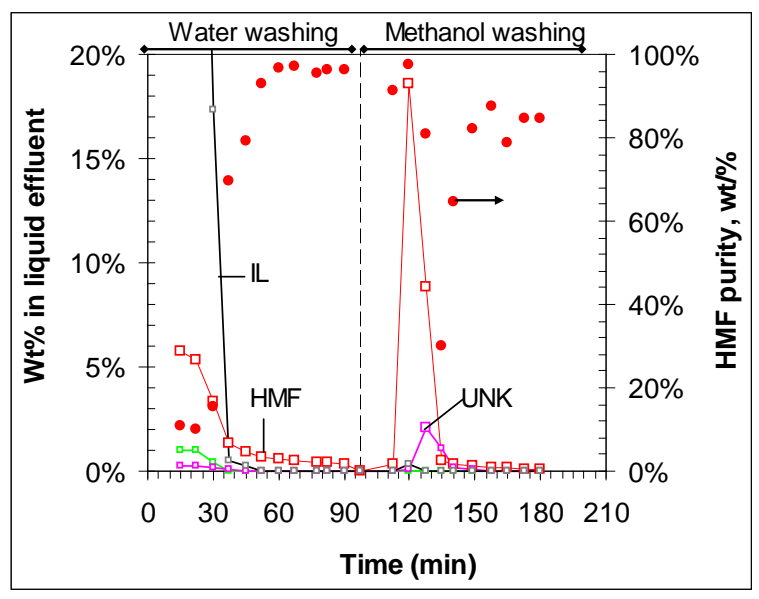

(b) Regeneration profile with water and $\mathrm{MeOH}$

Figure 6. Adsorption and regeneration profiles at $50^{\circ} \mathrm{C}$ of the nano-silicalite adsorbent column (Ionic liquid \#2 reaction mixture; FRU = fructose, $\mathrm{UNK}$ = by product; $\mathrm{IL}=$ ionic liquid, HMF purity $=\mathrm{HMF} /(\mathrm{HMF}+\mathrm{FRU}+\mathrm{UNK}+\mathrm{IL}))$.

\section{Different solvent flushing was tried but not effective in increasing HMF purity.}

HMF purity obtained from different adsorbent columns is still less than the $99 \%$ target. Because the ionic liquid is not volatile, it has to be completely washed out prior to HMF desorption in order to obtain high purity HMF. Instead of water, toluene and n-hexane was tried to flush the ionic liquid out of the adsorbent column. Washing by the organic solvent was no effective for removal of the ionic liquid, and the organic solvent washing reduced HMF adsorption capacity.

Solvent extraction of HMF from the ionic liquid has been quickly examined. Recent literature publications on HMF separation from a reaction mixture have been reviewed. Solvent extraction was a common method used in the literature. However, the reported HMF solubility numbers were generally small ( $<5 \mathrm{wt} \%)$. To confirm the present adsorption be the most effective separation method, solvent extraction was briefly evaluated with current water-miscible 
and water-immiscible ionic liquid fluids. The solvents evaluated during this period include water, methanol, ethanol, isopropyl alcohol (IPA), diethyl ether, ethylene glycol, acetonitrile, 1,4dioxane, dimethyl sulfoxide (DMSO), methyl isobutyl ketone (MIBK), tetrahydrofuran (THF), dichloromethane, hexane, toluene, iso-octane, and m-xylene. Although several organic solvents showed a higher HMF solubility than the common MIBK solvent, the HMF solubility is substantially lower than the adsorption capacity on the present solid adsorbent. Thus, the solvent extraction effort has been stopped.

\section{The super critical $\mathrm{CO}_{2}$ extraction of $\mathrm{HMF}$ from the ionic liquid has also been}

evaluated. $\mathrm{CO}_{2}$ is one common supercritical fluid (Tc $=31.04^{\circ} \mathrm{C}, \mathrm{Pc}=73.8$ bar or 1070 psia). No literature report has been found about HMF extraction by use of supercritical $\mathrm{CO}_{2}$. The literature review and analysis, however, suggested that the supercritical $\mathrm{CO}_{2}$ may provide high solubility for non-polar compounds, such as aromatics, and poor solubility for polar compounds, such as ionic liquids. The proof of concept testing was conducted on a laboratory setup illustrated in Figure 7. HMF extraction from the ionic liquids was tried at temperatures around $50^{\circ} \mathrm{C}$ and at pressures from 1000 to 2500psia. As expected, the ionic liquid uptake into the supercritical $\mathrm{CO}_{2}$ was too small to be analyzed. However, $\mathrm{HMF}$ absorption capacity in the supercritical $\mathrm{CO}_{2}$ phase was small, less than 0.5 wt.\%.

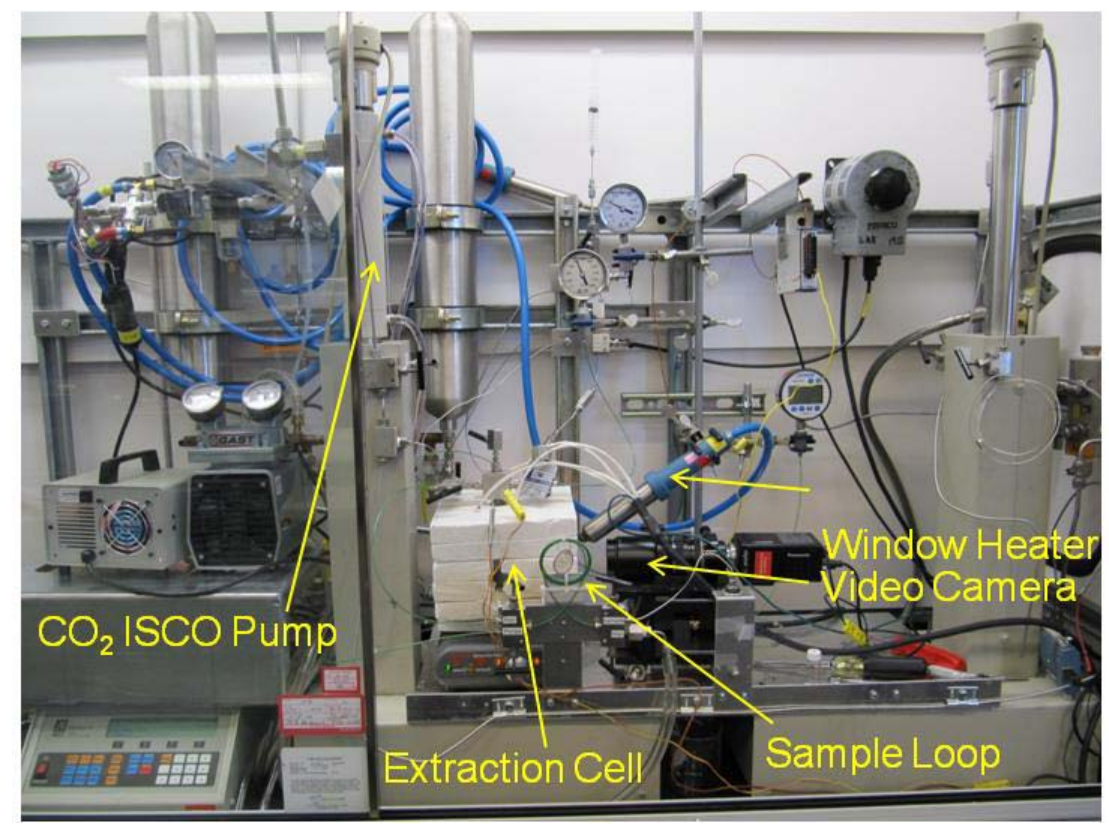

Figure 7. Schematic of experimental apparatus for super critical $\mathrm{CO}_{2}$ extraction of HMF from ionic liquid. 
In summary, the adsorbent invented in this work still appears to be the most promising approach for HMF separation from an ionic liquid reaction mixture, based on the literature review and experimental validation of other alternative separation methods. The ionic liquid discovered in this work still provides the best activity and selectivity for conversion of fructose conversion into HMF as compared to the other catalytic approaches reported in the literature.

Identification of adsorbent columns for HMF product isolation. A significant amount of effort was devoted toward optimizing column packing and operation conditions to obtain 99\% pure HMF product. As listed in Table 7, different sizes of the columns and different adsorbent materials were tried. The columns \#10-15 were packed with the powder-form zeolite adsorbent material, while the last column was packed with the engineered particles prepared in-house. All these adsorbent materials showed separation function of the ionic liquid reaction mixture. The main difficulty experienced in the research work was efficient purge of the ionic liquid residual in the column during regeneration step and collection of sufficient amounts of the regeneration effluent for HMF production isolation. After many times of trials, Column\#13 of 10mm in internal diameter and 250mm in length, loaded with the commercial organic-philic zeolite (OPZ) material, was chosen for extensive adsorption/regeneration tests.

Table 7. Adsorbent columns evaluated for separation of high purity HMF.

\begin{tabular}{|c|c|c|c|c|c|c|}
\hline ID \# & $\begin{array}{l}\text { Column Size } \\
(\mathrm{mm} \times \mathrm{xmm})\end{array}$ & Adsorbent material & $\begin{array}{l}\text { Packed } \\
\text { Weight } \\
\text { (g) }\end{array}$ & $\begin{array}{l}\text { Packing } \\
\text { Density } \\
\text { (g/cc) }\end{array}$ & $\begin{array}{l}\text { Pore } \\
\text { Volume } \\
\text { (cc/g) }\end{array}$ & $\begin{array}{l}\text { Void } \\
\text { Fraction }\end{array}$ \\
\hline 10 & $\Phi 4.6 \times 150$ & \multirow{2}{*}{$\begin{array}{l}\text { Nano-silicalite powder prepared } \\
\text { in-house (31510-1-24) }\end{array}$} & 2.5 & 0.99 & 0.54 & 0.54 \\
\hline 11 & $\Phi 22 \times 70$ & & 27.5 & 1.03 & 0.48 & 0.50 \\
\hline 12 & $\Phi 22 \times 70$ & \multirow{2}{*}{$\begin{array}{l}\text { Organic Philic Zeolite (OPZ) } \\
\text { powder from commercial source }\end{array}$} & 21.6 & 0.81 & 0.72 & 0.58 \\
\hline 13 & $\Phi 10 \times 250$ & & 14.6 & 0.74 & 0.82 & 0.61 \\
\hline 14 & $\Phi 10 x 250$ & $\begin{array}{l}\mathrm{NH} 4-\mathrm{ZSM}-5\left(\mathrm{SiO}_{2} / \mathrm{Al}_{2} \mathrm{O}_{3}=280\right) \\
\text { powder from commercial source }\end{array}$ & 19.5 & 0.99 & 0.47 & 0.47 \\
\hline 15 & $\Phi 10 x 250$ & $\begin{array}{l}\text { Nano-silicalite powder in-house } \\
\text { prepared }(5610 / 5710)\end{array}$ & 19.0 & 0.97 & 0.53 & 0.51 \\
\hline 16 & $\Phi 10 \times 250$ & $\begin{array}{l}\text { Encapsulated OPZ particle in- } \\
\text { house prepared ( } 45-140 \text { mesh) }\end{array}$ & 15.0 & 0.76 & 0.91 & 0.70 \\
\hline
\end{tabular}


Recovery of $\mathbf{9 9 \%}$ pure HMF product and ionic liquid. The column \#13 was tested for eight adsorption/regeneration cycles to establish reproducibility, generate enough samples for recovery of the ionic liquid and HMF product, and conduct material balances. The representative adsorption and regeneration profiles are shown in Figures 8 and 9, respectively. Both adsorption and regeneration was conducted at $50^{\circ} \mathrm{C}$. In the adsorption testing, an ionic liquid reaction batch was quenched and diluted with de-ionized water by about 1:1 weight ratio, the resulting mixture was fed into the column at $0.94 \mathrm{cc} / \mathrm{min}$, and the effluent was periodically collected and analyzed by a standardized HPLC method. It is noted that four HPLC peaks at residence times of 5.3, 7.4, 14.1, and 21.3min have not been identified, since the peak position does not match the calibration compound in our data base. They could be the reaction intermediates, side products, and impurities. Thus, only identified species, ionic liquid, fructose, glucose HMF, are plotted in the adsorption and regeneration profiles.

As shown in Figure 8, the ionic liquid, fructose, and glucose came out together as the feed passed through the adsorption column. It took about 90min for HMF breakthrough to occur. After the column was saturated by HMF, the column was first purged by nitrogen gas to remove the bulk fluid in the system and then, the column was flushed by de-ionized water for $60 \mathrm{~min}$ and by methanol for $60 \mathrm{~min}$.

As shown in Figure 9, the ionic liquid and fructose retained among inter-particle voids were rapidly washed out of the column by water, while the adsorbed HMF inside the zeolite pore was intact. Upon switching to methanol washing, HMF product came out immediately, reached a peak, and then, declined. Compared to $2.4 \mathrm{wt} \%$ in the adsorption feed, HMF content was dramatically enriched in the methanol flushing effluent. At the peak, the HMF content was as high as $29 \mathrm{wt} \%$. However, there was still some residual ionic liquid that came out in the late stage of the methanol flushing. This small fraction of ionic liquid may be due to the ionic liquid that was trapped at the defect sites of the zeolite crystal. 


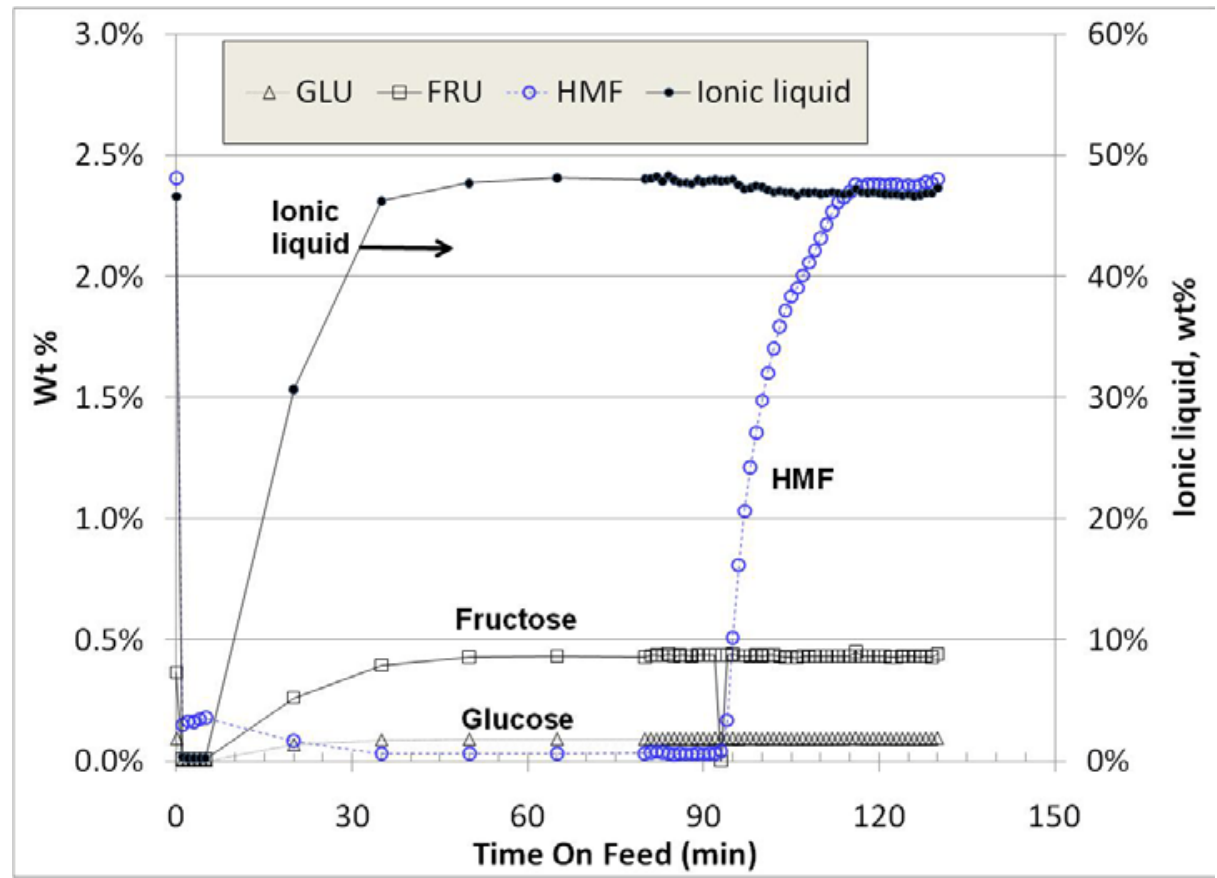

Figure 8. Typical adsorption breakthrough curves with an ionic liquid reaction mixture (Column\#13, $50^{\circ} \mathrm{C}, 0.944 \mathrm{cc} / \mathrm{min}$ of feed rate).

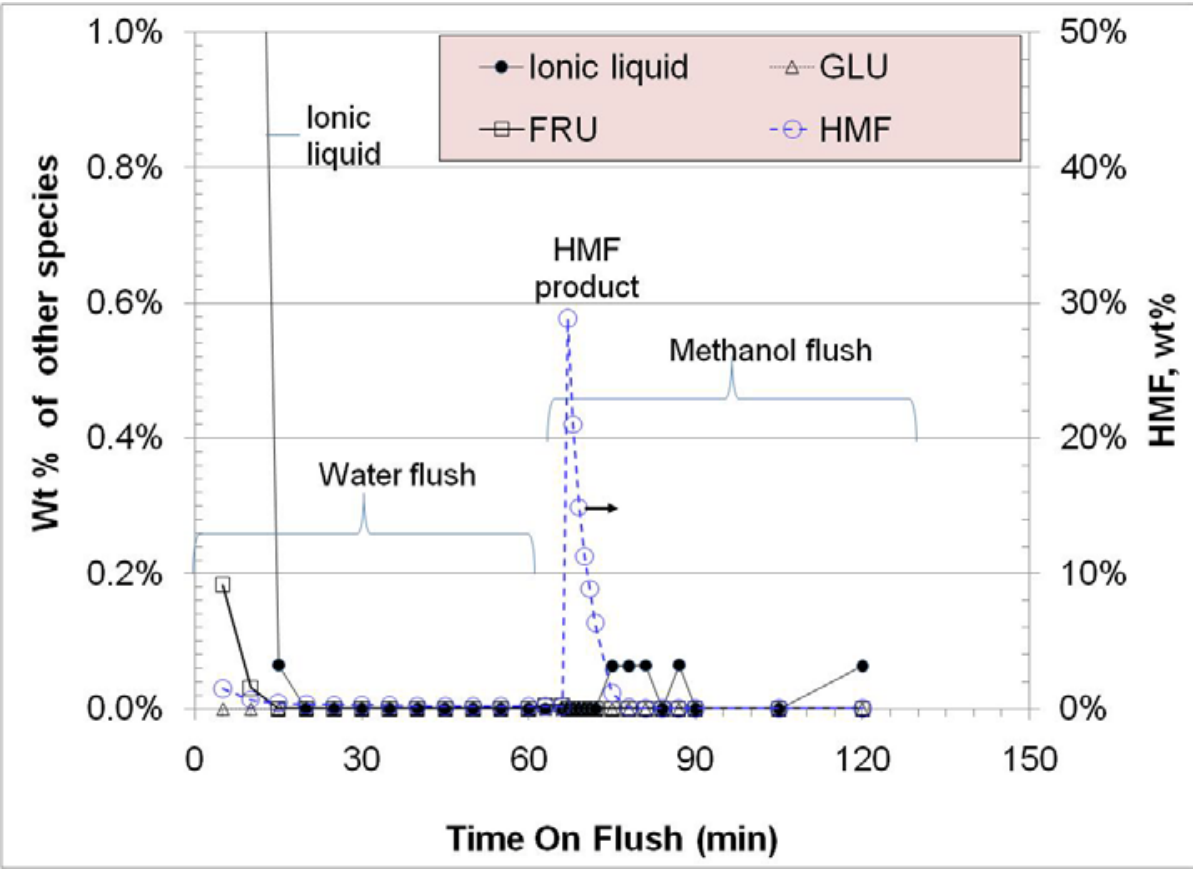

Figure 9. Typical regeneration profiles (Column\#13, $50^{\circ} \mathrm{C}, 2.0 \mathrm{cc} / \mathrm{min}, 60-\mathrm{min}$ water flushing followed by 60-min methanol flushing). 
Based on the adsorption and regeneration profiles, the following samples were collected and processed. Sample \#1 was the column effluent collected during the adsorption stage. Sample \#2 is the column effluent collected during the water flushing stage. Samples \#3- \#6 are the column effluent collected at the beginning, peak positions, and the late stage of the methanol flushing, respectively. Methanol and water was removed out of the collected liquid sample by using Rotatory Evaporation under 10torr and High Vacuum Schlenk Line under 83 mtorr. All the drying processes were conducted at room temperature to minimize the side reactions. The resulting product and by-product samples are illustrated in Figure 10.

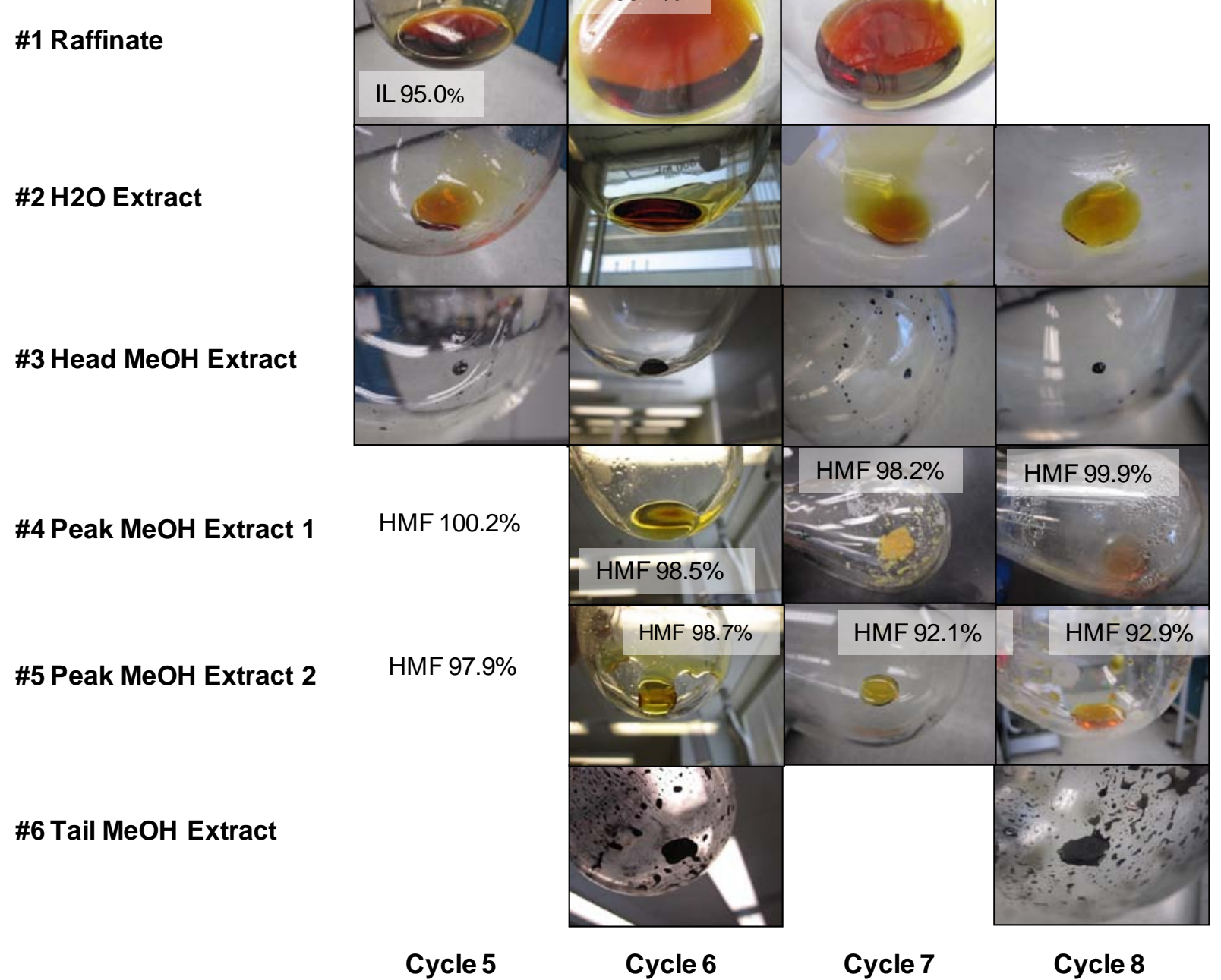

Figure 10. Dried product and by-product samples isolated from different steps of an adsorption/regeneration cycle (Column \#13). 
HMF product samples of purity from 98 to $100 \%$ were finally isolated from the methanol flushing effluents of concentrated HMF content. As a comparison, a HMF product purchased from Sigma-Aldrich showed a purity of $96.7 \%$ by using the same HPLC analytical method. Samples \#1 and \#2 are the recovered ionic liquid with un-converted fructose, reaction intermediates, and glucose as the minor constituents. The residual obtained from drying of Sample \#3 could not be identified yet, while sample\#6- tail methanol extract mostly consists of the ionic liquid and HMF product. Compositions of these product samples are listed in the material balance sheet below.

Table 8. Mass balances of adsorption/regeneration cycle (Column \#13).

\begin{tabular}{|l|l|l|l|l|l|l|l|}
\hline \multirow{2}{*}{$\begin{array}{l}\text { Sample } \\
\#\end{array}$} & \multirow{3}{*}{$\begin{array}{l}\text { Mass Distribution of Cycle \#5 } \\
\text { (g) }\end{array}$} & \multicolumn{4}{c|}{ Mass Distribution of Cycle \#6 (g) } \\
\cline { 3 - 8 } & Description & 56.34 & 2.91 & 0.44 & 57.79 & 2.98 & 0.45 \\
\hline & Feed & 52.86 & 0.86 & 0.58 & 53.18 & 0.86 & 0.40 \\
\hline$\# 1$ & Raffinate & 2.98 & 0.51 & 0.02 & 3.49 & 0.56 & 0.04 \\
\hline$\# 2$ & $\mathrm{H}_{2} \mathrm{O}$ extract & 0.00 & 0.02 & 0.00 & 0.00 & 0.02 & 0.00 \\
\hline$\# 3$ & Head MeOH extract & & 0.87 & & & 0.82 & \\
\hline$\# 5$ & Peak MeOH extract 1 & & 0.32 & & & 0.48 & \\
\hline$\# 6$ & Peak MeOH extract 2 & & 0.11 & & 0.01 & 0.07 & \\
\hline \multicolumn{2}{l}{ Mass balance, out/in } & 9.02 & $92.5 \%$ & $137.6 \%$ & $98.1 \%$ & $94.2 \%$ & $97.2 \%$ \\
\hline
\end{tabular}

Table 9. Total mass balances of adsorption/regeneration cycle (Column\#13, Cycle 6)

\begin{tabular}{|c|c|c|c|c|c|c|c|c|c|c|c|c|c|c|c|}
\hline \multirow[b]{2}{*}{$\begin{array}{c}\text { Total Mass } \\
\text { Balance }\end{array}$} & \multirow[b]{2}{*}{$101.4 \%$} & \multicolumn{6}{|c|}{ Feed } & \multicolumn{6}{|c|}{ Effluent } & \multicolumn{2}{|c|}{ Hold-up } \\
\hline & & \multicolumn{2}{|c|}{ Feed Loading } & \multicolumn{2}{|c|}{ H2O Wash } & \multicolumn{2}{|c|}{ MeOH Wash } & Raffinate & H2O Extract & $\begin{array}{l}\text { Head } \\
\text { MeOH } \\
\text { Extract }\end{array}$ & $\begin{array}{l}\mathrm{Pk} \mathrm{MeOH} \\
\text { Extract } 1\end{array}$ & $\begin{array}{l}\text { Pk MeOH } \\
\text { Extract } 2\end{array}$ & $\mid \begin{array}{c}\text { Tail } \mathrm{MeOH} \\
\text { Extract }\end{array}$ & \multicolumn{2}{|c|}{$\begin{array}{c}\text { (due to density diff. of } \\
\text { H2O \& MeOH) }\end{array}$} \\
\hline \multirow{5}{*}{\multicolumn{2}{|c|}{ Density (g/ml ) }} & Trial 1 & 1.0447 & At $22^{\circ} \mathrm{C}$ & 0.9976 & At $22^{\circ} \mathrm{C}$ & 0.7902 & & & & & & & & \\
\hline & & Trial 2 & 1.0363 & & & & & & & & & & & & \\
\hline & & Trial 3 & 1.0383 & & & & & & & & & & & & \\
\hline & & Mean & 1.0398 & & & & & & & & & & & & \\
\hline & & STDEV & 0.0044 & & & & & & & & & & & & \\
\hline \multirow{6}{*}{\multicolumn{2}{|c|}{ Pump Volume (ml) }} & Start & 129.2147 & Start 1 & 99.2226 & Start & 138.9719 & & & & & & & Void Frac & 0.607 \\
\hline & & Stop & 10.14073 & Stop 1 & 6.526327 & Stop & 20.00245 & & & & & & & Colmn Vol & 19.63 \\
\hline & & Change & 119.074 & \begin{tabular}{|l|} 
Change 1 \\
\end{tabular} & 92.69627 & Change & 118.9695 & & & & & & & \begin{tabular}{|l|} 
Void Vol \\
\end{tabular} & 11.91 \\
\hline & & & & Start 2 & 50.24775 & & & & & & & & & & \\
\hline & & & & Stop 2 & 17.54896 & & & & & & & & & & \\
\hline & & & & \begin{tabular}{|l} 
Change 2 \\
\end{tabular} & 32.6988 & & & & & & & & & & \\
\hline \multicolumn{2}{|c|}{ Run Time (min) } & \multicolumn{2}{|c|}{120} & \multicolumn{2}{|c|}{\begin{tabular}{|c|}
60 \\
\end{tabular}} & \multicolumn{2}{|c|}{60} & 120 & 60 & 6 & 2 & 2 & 50 & & \\
\hline \multicolumn{2}{|c|}{ Flow Rate $(\mathrm{ml} / \mathrm{min})$} & \multirow{2}{*}{\multicolumn{2}{|c|}{$\begin{array}{c}0.992 \\
123.81\end{array}$}} & \multicolumn{2}{|c|}{2.090} & \multicolumn{2}{|c|}{1.983} & & & & & & & & \\
\hline \multicolumn{2}{|c|}{ Mass (g) } & & & 125 & .09 & & .01 & 126.48 & 121.12 & 11.54 & 5.09 & 4.83 & 78.75 & \multicolumn{2}{|c|}{2.47} \\
\hline Total $\mathbf{M}$ & ass $(\mathrm{g})$ & \multicolumn{6}{|c|}{342.91} & \multicolumn{6}{|c|}{347.81} & \multicolumn{2}{|c|}{0.00} \\
\hline
\end{tabular}

Material balances of the adsorption/regeneration cycle. Material distributions of the ionic liquid, HMF, and fructose are shown in Table 8 for adsorption/regeneration cycles \#5 and 
\#6. The mass balance of a given compound is calculated as ratio of a total amount collected from the regeneration to the amount fed into the column. The ionic liquid is dominantly ended up in the sample \#1- raffinate, while majority of HMF product exists in the peak portions of the methanol flushing. The mass balance of HMF is consistently less than $95 \mathrm{wt} \%$.

Total mass balance of the adsorption/regeneration run is illustrated by results listed in Table 9, which was obtained from Cycle \#6. The total weight of samples collected from the column effluent is $101.4 \%$ of the total amount of materials fed into the column. One main problem for total mass balance was that state of the adsorbent column before the adsorption and after the regeneration could be controlled and measured accurately in the current laboratory testing system.

Stability of HMF was checked with a pure HMF product (Sigma Aldrich) under the adsorption/regeneration conditions, under the product drying conditions, and under storage. The same experimental procedure was used as for the actual adsorption/regeneration and product recovery. It was found that HMF was stable under the current adsorption and regeneration conditions. However, HMF recovery was only 91.5\% after going through the vacuum drying process at room temperature, which explains $<95 \%$ of HMF recovery from the ionic liquid reaction mixture. Amounts of the HMF going through the recovery process were so small that a little loss during the sample transfer could reduce the HNF recovery. It was also found that HMF in the ionic liquid reaction mixture was highly unstable when being stored under ambient air conditions. More than 50\% of HMF in the ionic liquid could be lost after storage in air at room temperature for $21 \mathrm{~h}$. This loss was due to conversion of HMF into some un-identified species such as polymers. HMF loss can be minimized by storage inside a refrigerator.

Preparation of membrane-coated adsorbent particles. HMF product recovery with silicalite adsorbent in powder form was successfully shown in the previous report. However, the adsorption column loaded with the zeolite powder had very large pressure drops, which was obviously not practical for large-scale or industrial separation processes. One problem was that the silicalite powder is difficult to be pelletized due to its high hydrophobicity. Addition of common binding materials would make the silicalite lose its hydrophobicity. Another problem is retention of the ionic liquid inside pores of an engineered particle. The conventional adsorbent particle often contains meso- and macro-pores. The ionic liquid may be readily trapped inside those pores during adsorption that becomes very difficult to be purged out due to low diffusivity 
of ionic liquids. It would not be possible to obtain pure HMF without complete purging of the ionic liquid prior to HMF desorption.

To address these problems, we discovered a new way to prepare an engineered particle as shown in Figure 11. Basically, an agglomerate of zeolite crystals are encapsulated with a thin $(<20 \mu \mathrm{m})$ silicalite membrane layer to form an adsorbent particle. Penetration of ionic liquids into inter-crystal voids is blocked by the zeolite membrane, while the micro-pores of the zeolite membrane allow HMF and solvent molecules transport between the interior of the particle and bulk fluid. The silicalite membrane layer is so thin relative to the particle size that it does not impose significant mass transfer resistance.

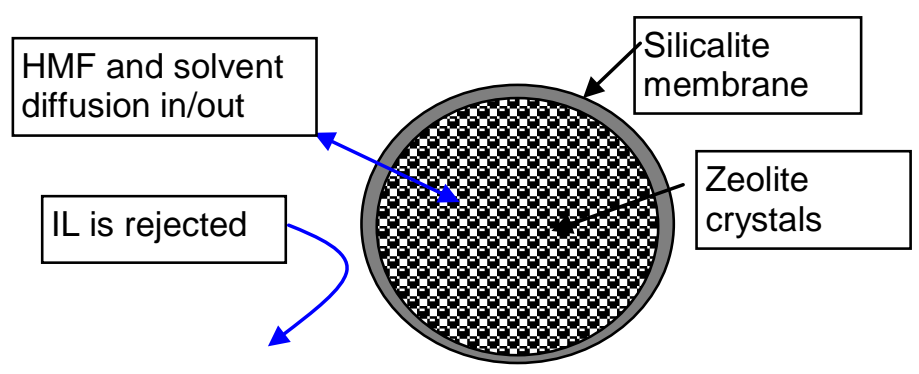

Figure 11. Membrane-coated adsorbent particle.

Several different types of engineered particles were prepared this period with the design model illustrated in Figure 11 and tested in an adsorption column. Table 10 lists adsorbent materials and column loading properties. The adsorbent particles were prepared with two different approaches.

In Method I, a silicalite-type zeolite membrane was grown on exterior surface of a preformed adsorbent particle that can be made in various shapes, beads, extrudates, crushed particles. In principle, the silicalite membrane can be grown on any porous adsorbent particle with the membrane growth method invented in this work. For HMF separation application here, we tested commercial 13X beads, commercial ZSM-5 extrudate that was crushed into desired particle sizes, and OPZ particles prepared in-house. They were tested in the column \#17, \#16, and \#21, respectively.

In Method II, loose zeolite powder was made into agglomerates of desirable sizes by using the parent silicalite growth solution. After drying, the agglomerates were immersed into the zeolite growth solution and the membrane growth was conducted in an autoclave reactor. The 
original zeolite crystals inside the agglomerate were bonded together through inter-crystal growth, as the exterior meso- and macro-pores of the agglomerates were sealed up by the membrane growth. The original agglomerates were very weak and became mechanically strong after the growth. Both in-house prepared silicalite powder and commercial OPZ powder were used to make the engineered adsorbent particle in such a way. They were tested in Column\# 20 and \#19, respectively.

Table 10. Membrane-coated adsorbent particles prepared and tested this period.

\begin{tabular}{|c|c|c|c|c|c|c|c|c|}
\hline \multirow{2}{*}{ ID } & $\begin{array}{c}\text { Column } \\
\text { Size } \\
(\mathrm{mm})\end{array}$ & $\begin{array}{c}\text { Material/Preparation } \\
\text { method }\end{array}$ & $\begin{array}{c}\text { Packed } \\
\text { Weight }\end{array}$ & $\begin{array}{c}\text { Void } \\
\text { Volume }\end{array}$ & $\begin{array}{c}\text { Packing } \\
\text { Density }\end{array}$ & $\begin{array}{c}\text { Void } \\
\text { Fraction }\end{array}$ & $\begin{array}{c}\text { True } \\
\text { Density }\end{array}$ & $\begin{array}{c}\text { Pore } \\
\text { Volume }\end{array}$ \\
\cline { 4 - 9 } & & {$[\mathrm{g}]$} & {$[\mathrm{ml}]$} & {$[\mathrm{g} / \mathrm{ml}]$} & {$[-]$} & {$[\mathrm{g} / \mathrm{ml}]$} & {$[\mathrm{ml} / \mathrm{g}]$} \\
\hline$\# 16$ & $\Phi 10 \times 250$ & $\begin{array}{c}\text { Silicalite-coated OPZ* } \\
\text { particle (45- } \\
\text { 140mesh)/Method I }\end{array}$ & 15.0 & 13.7 & 0.765 & $69.9 \%$ & 2.54 & 0.91 \\
\hline$\# 18$ & $\Phi 22 \times 70$ & $\begin{array}{c}\text { Silicalite-coated 13X } \\
\text { beads/Method I }\end{array}$ & 20.4 & 16.7 & 0.765 & $62.9 \%$ & 2.06 & 0.82 \\
\hline$\# 19$ & $\Phi 7 \times 250$ & $\begin{array}{c}\text { Silicalite-coated OPZ } \\
\text { powder (60040-37- } \\
\text { 2)/Method II }\end{array}$ & 11.5 & 9.5 & 0.583 & $48.6 \%$ & 1.13 & 0.83 \\
\hline$\# 20$ & $\Phi 7 \times 250$ & $\begin{array}{c}\text { Silicalite-coated } \\
\text { silicalite powder } \\
\text { (60040-37-3)/Method II }\end{array}$ & 10.6 & 6.9 & 0.538 & $35.0 \%$ & 0.83 & 0.65 \\
\hline$\# 21$ & $\Phi 7 \times 250$ & $\begin{array}{c}\text { Silicalite-coated ZSM-5 } \\
\text { particle (45-140mesh) } \\
(60040-123-1) / \text { Method I }\end{array}$ & 8.3 & 9.2 & 0.422 & $47.0 \%$ & 0.80 & 1.11 \\
\hline$\# 22$ & $\Phi 7 \times 250$ & $\begin{array}{c}\text { 13X Beads (60040-37- } \\
\text { 4) }\end{array}$ & 7.1 & 6.1 & 0.363 & $31.2 \%$ & 0.53 & 0.86 \\
\hline
\end{tabular}

${ }^{*} \mathrm{OPZ}=$ organic-philic zeolite (Aldrich)

\section{Adsorption separation tests of the membrane-coated adsorbent particle. The} outstanding performance of the adsorbent particle prepared in this work is illustrated by the adsorption and desorption profiles in Figure 12. An ionic liquid reaction mixture was obtained by converting fructose feedstock into HMF product. The adsorption breakthrough profiles in Figure 12a show that the pressure drop across the column was only 14 psi through the adsorption process, and HMF breakthrough occurs about 40min later than fructose. Selective adsorption of HMF over the ionic liquid and fructose is clearly shown. The small pressure drop makes a practical adsorption separation process feasible. The pressure drop obtained with the engineered 
particle is one to two orders of magnitude less than the column packed with zeolite powder materials.

Once the adsorbent is saturated, the column is flushed with de-ionized water to remove the feed solution trapped inside the column. It was very difficult to wash out the residual ionic liquid from conventional adsorbent particle beds due to high viscosity of the ionic liquid. Figure $12 \mathrm{~b}$ shows that the ionic liquid is quickly washed out of the column loaded with the membranecoated adsorbent particle by water, and the pressure drop during water flushing is small. Subsequently, the adsorbed HMF product is desorbed from the zeolite pores by methanol washing. Figure 12c shows that HMF is rapidly released during methanol washing and desorbed HMF has a higher concentration than that in the reaction mixture. This indicates enrichment of HMF product by the adsorption separation. There is no residual ionic liquid emerged during the methanol washing, which suggests the possibility to produce high purity HMF product. 


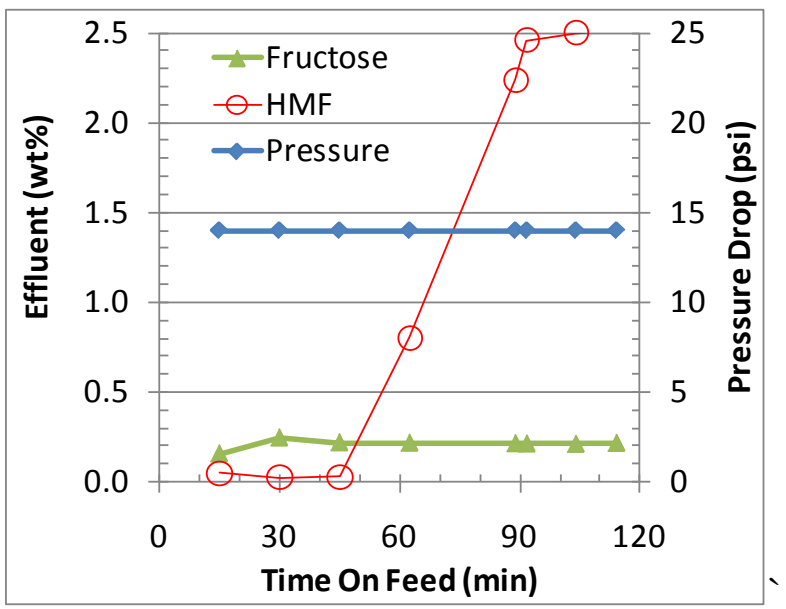

(a) Adsorption breakthrough profile

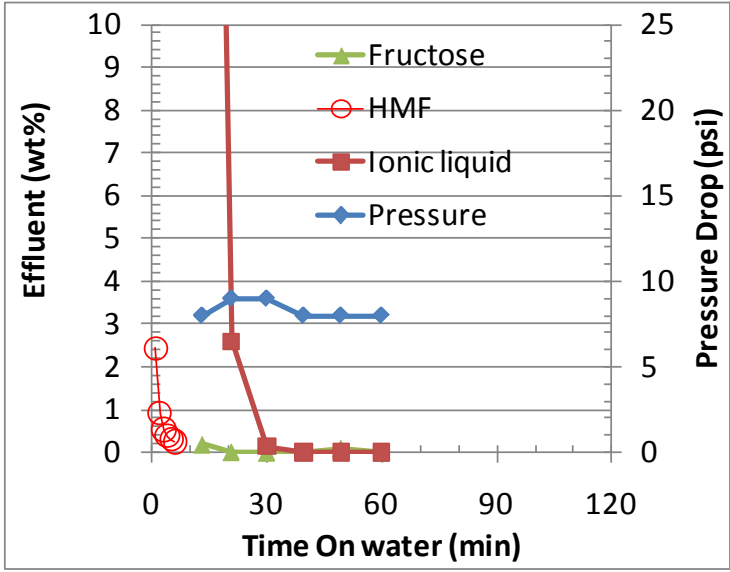

(b). Water flush of saturated column

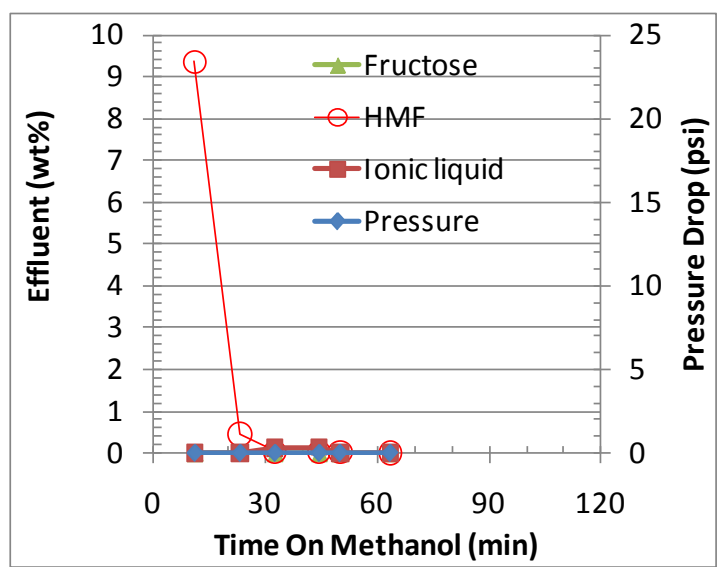

(c). Desorption with methanol washing

Figure 12. Adsorption separation performances of a column packed with silicalite membrane-coated silicalite particles (Column $\# 19$, at $50^{\circ} \mathrm{C}$ ) with a fructose ionic liquid reaction mixture.

The outstanding separation performance of the membrane-coated zeolite particles is further demonstrated with an ionic liquid reaction mixture derived from cellulose feedstock. Different from the previous fructose feedstock, the cellulose feedstock resulted in relatively low HMF concentration (0.68 wt\%) and possibly a lot of byproducts. Figure 13a shows that the HMF breakthrough does not occur during the adsorption time period tested due to the low HMF content in the ionic liquid reaction mixture. The pressure drop is small during the adsorption. The residual ionic liquid in the column is quickly washed out with water (Figure 13b), and the subsequent methanol flushing results in a concentrated HMF peak of no ionic liquid (Figure 13c). The present results show the possibility to produce high purity HMF from ionic liquid catalytic processes with cellulose feedstock. 


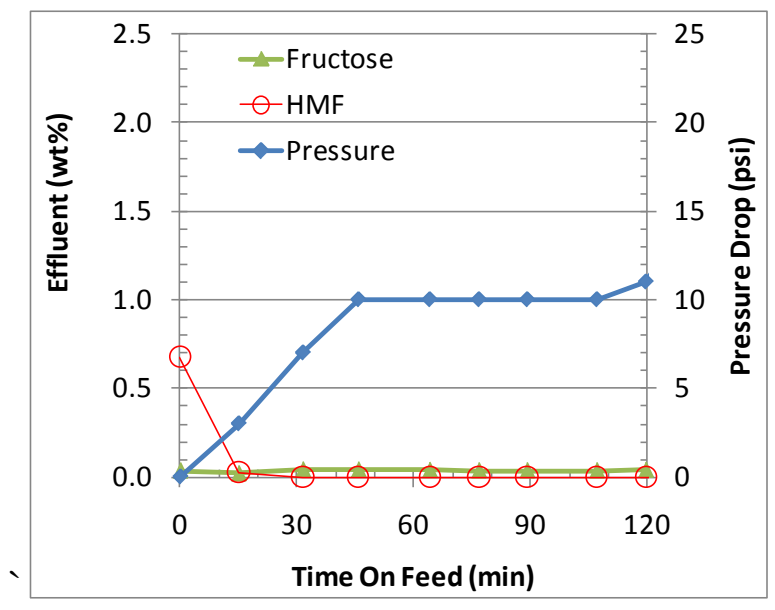

(a) Adsorption breakthrough profile

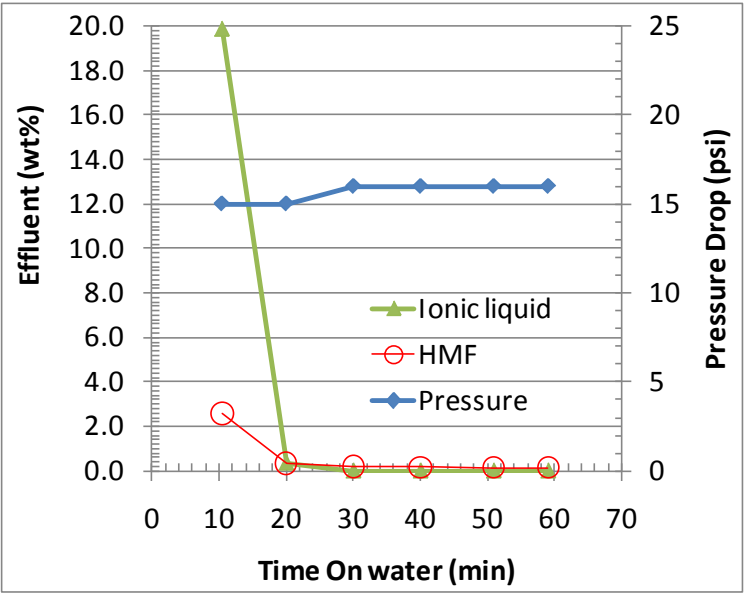

(b) Water flush of saturated column

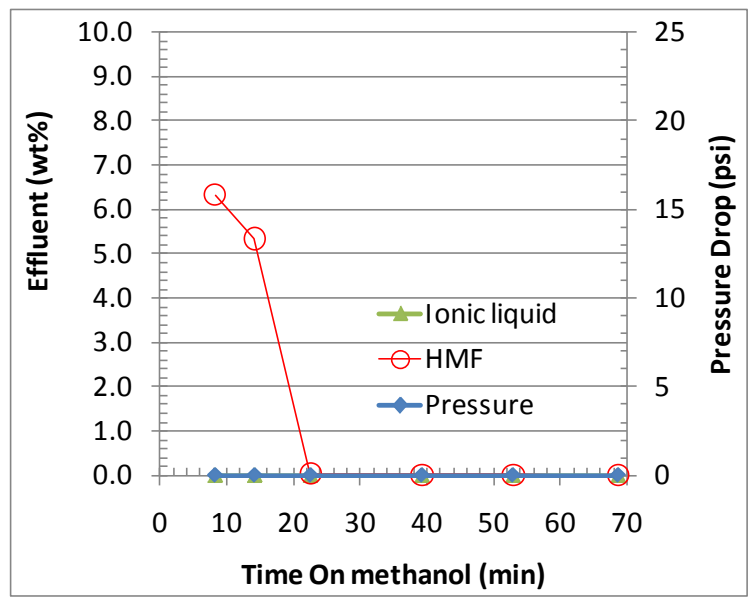

(c) Desorption with methanol washing

Figure 13. Adsorption separation performances of a column packed with silicalite membrane-coated silicalite particles (Column \#19, at $50^{\circ} \mathrm{C}$ ) with a cellulose ionic liquid reaction mixture (\#1 extracted batch soln from Run\# 60763-79-1).

Significant results achieved under task 2 are summarized as follows:

- Effective adsorbent materials for selective HMF adsorption are identified

- Silicalite material of small, uniform, and pure crystals is prepared and demonstrated for superior performances over the commercial powder

- Membrane-coated zeolite adsorbent particles are prepared and demonstrated to provide the adsorption performance same as in powder form but with much low pressure drops. 
- A practical adsorption process is invented and demonstrated for separation of pure (99\%) HMF from ionic liquid reaction mixtures

- The adsorption process involves a relatively simple process flow diagram, and is much more efficient than other separation means such as solvent extraction.

- The adsorption process should be applicable to product separation from other ionic liquid or water-based catalytic reaction mixtures.

- Adsorbent materials and adsorption process have been demonstrated for separation of 99\% pure HMF product from ionic liquid reaction mixtures.

\subsection{Task 3 - Evaluation of biomass feedstock}

The activities conducted under this task include (i) screening tests of an optimum catalyst system identified in earlier research, new ionic liquids and additives; (ii) parametric tests of ballmilled mixtures in a Parr reactor; (iii) Reaction tests in a beaker on a hot plate

Reaction conversion of cellulose. Conversion of fructose into HMF was worked out in first two years of the project, which is a simple reaction process. However, fructose is considered as an expensive, food-grade feedstock. Thus, the research effort has been focused on enhancement of cellulose conversion efficiency for this period. The following experimental work was performed to identify effective catalyst/ionic liquid systems:

(i) A series of batch reactor tests with an optimum catalyst/ionic liquid system discovered through combinatorial experiments in earlier exploratory research at PNNL prior to this project (1). Compared to a small amount of reaction mixture loading in the combinatorial sample vial ( $\sim 500 \mathrm{mg})$, about $75 \mathrm{~g}$ of the reaction mixture was loaded into a Parr autoclave reactor for current batch testing and the reaction was conducted under continuous stirring.

(ii) Combinatorial chemistry screening tests of different ionic liquids, catalyst materials, biomass species (cellulose, glucose, sucrose), and additives.

Both cellulose conversion and HMF yield obtained from the batch reactor testing were substantially lower than what was reported previously for the combinatorial experimental results (1). For example, cellulose conversion was only about $30 \mathrm{wt} \%$ versus $>90 \%$. Furthermore, the un-converted cellulose and ionic liquid could not be separated from the final reaction mixture. 
The conversion efficiency could not be improved by changing batch reactor conditions, such as stirring speed, temperature and reaction time.

The earlier combinatorial results could not be reproduced in current combinatorial experiments either. The cellulose conversion was lower than 50\%, though the current screening tests indeed showed the $\mathrm{CuCl}_{2}-\mathrm{CrCl}_{2} /[\mathrm{emin}] \mathrm{Cl}$ as the most active catalyst system. This finding is consistent with the previous combinatorial discovery. There was no apparent advantage to use glucose feedstock over cellulose. As a result, the research focus was shifted toward cellulose.

The project activities were halted for a few months due to the above problems. Later we found that mixing of cellulose in the ionic liquid was the biggest problem even if the cellulose loading was only $10 \mathrm{wt} \%$. The cellulose was not well dispersed into the ionic liquid either in combinatorial sample vials by shaking or in a batch reactor by stirring. Several mixing methods were tried. It turned out that a ball-milling method is an effective means for mixing of cellulose with ionic liquids. Thus, the research activity has been rejuvenated recently. A series of batch reactor tests have been conducted. The research results are illustrated with four batch runs listed in Table 11. About $75 \mathrm{~g}$ of a mixture of reactants was first ball milled and then transferred into a Parr reactor for reaction testing. The reaction mixture was sampled at different times during the run. The sample was diluted with de-ionized water and analyzed by HPLC. The product wt\% in the reaction mixture was back calculated from HPLC analytical results and water dilution factor. Cellulose conversion is estimated based on wt\% in the reaction batch.

The ball-milling mixing allows $25 \mathrm{wt} \%$ cellulose loading in the reaction mixture, which is substantially higher than 5 to $10 \mathrm{wt} \%$ used in the previous literature reports. Impacts of cellulose loading on conversion and product distribution are shown by comparing Run \#1 to Run\#2. In these runs, the cellulose and ionic liquid were first mixed by the ball-milling. Then, the catalyst was added after the mixture was transferred into the Parr reactor. The catalyst loading wt $\%$ was the same for the two reaction batches of different cellulose loading. The $25 \mathrm{wt} \%$ loading resulted in both HMF yield and cellulose conversion higher than the $10 \mathrm{wt} \%$ loading.

In Runs \#2 and \#3, the same ionic liquid but supplied by two vendors with different purity specifications was used. It can be seen that the reaction at $120^{\circ} \mathrm{C}$ was very fast. The conversion basically occurred within first one hour of the reaction, which is much shorter than eight hours used in the earlier work (1). The cellulose conversion did not increase with 
prolonging of reaction time. The cellulose conversion is above 50\%. The cheap, low-purity ionic liquid is equally effective as the high-purity one, which has significant practical implication.

Different from Runs \#1 to \#3, Run \#4 was conducted by adding the catalyst into the ballmilling batch together with cellulose and ionic liquid. Even though the catalyst loading wt\% was the same in all those runs, higher cellulose conversion and more HMF product were obtained in Run\#3. This is explained by better dispersion of the catalyst into the reaction mixture. The reaction results are promising for conversion of cellulose into a series of reaction products. More batch reaction tests are under way to identify an optimum set of conditions for cellulose conversion. Then, we will conduct separation of reaction mixtures for recovery of the catalyst/ionic liquid and reaction products.

Table 11. Conversion of cellulose in a $\mathrm{CuCl}_{2}-\mathrm{CrCl}_{2} /[\mathrm{EMIN}] \mathrm{Cl}$ catalyst/ionic system (batch reactor testing at $120^{\circ} \mathrm{C}$ with continuous stirring and $\mathrm{N} 2$ gas purge).

\begin{tabular}{|c|c|c|c|c|c|c|c|}
\hline \multirow{2}{*}{$\begin{array}{l}\text { Reaction } \\
\text { time, h }\end{array}$} & \multicolumn{6}{|c|}{ Reaction product distribution, wt.\% } & \multirow{2}{*}{$\begin{array}{l}\text { Cellulose } \\
\text { conversion \% }\end{array}$} \\
\hline & Glucose & Fructose & Unk & Formic acid & $\begin{array}{l}\text { Levulinic } \\
\text { acid }\end{array}$ & HMF & \\
\hline \multicolumn{8}{|c|}{ Run \#1: $10.0 \%$ cellulose loading in [EMIM]Cl (95\% purity) } \\
\hline 0.5 & 0.12 & 0.07 & 0.53 & 0.20 & 0.21 & 0.39 & 15.2 \\
\hline 1 & 0.18 & 0.09 & 0.69 & 0.15 & 0.21 & 0.77 & 20.8 \\
\hline 2.0 & 0.47 & 0.07 & 1.38 & 0.11 & 0.14 & 1.65 & 38.0 \\
\hline 4.0 & 0.88 & 0.10 & 1.97 & 0.12 & 0.12 & 2.55 & 57.1 \\
\hline \multicolumn{8}{|c|}{ Run \#2: $24.0 \%$ cellulose loading in [EMIM]Cl (95\% purity) } \\
\hline 1 & 3.09 & 0.33 & 6.43 & 0.59 & 0.22 & 4.86 & 64.7 \\
\hline 2 & 2.10 & 0.24 & 4.00 & 0.37 & 0.14 & 3.83 & 44.6 \\
\hline 3.5 & 2.75 & 0.31 & 5.26 & 0.53 & 0.18 & 4.62 & 56.9 \\
\hline 5.1 & 2.68 & 0.29 & 4.91 & 0.39 & 0.15 & 4.35 & 53.2 \\
\hline 6.5 & 2.62 & 0.26 & 4.52 & 0.44 & 0.11 & 4.11 & 50.2 \\
\hline \multicolumn{8}{|c|}{ Run\#3: $25.0 \%$ cellulose loading in [EMIM]Cl (99\% purity) } \\
\hline 0.5 & 2.35 & 0.32 & 4.78 & 0.71 & 0.43 & 4.78 & 53.5 \\
\hline 1 & 2.42 & 0.30 & 3.75 & 0.43 & 0.24 & 5.60 & 50.9 \\
\hline 2.0 & 1.85 & 0.35 & 5.20 & 0.58 & 0.00 & 6.00 & 55.9 \\
\hline 4.0 & 1.75 & 0.35 & 4.91 & 0.59 & 0.02 & 5.18 & 51.2 \\
\hline \multicolumn{8}{|c|}{ Run\#4: $25.1 \%$ cellulose loading in [EMIM]Cl (95\% purity) with catalyst added during mixing } \\
\hline 0.5 & 2.09 & 0.28 & 5.73 & 0.47 & 0.29 & 7.31 & 64.5 \\
\hline 1 & 2.08 & 0.27 & 5.63 & 0.41 & 0.34 & 7.21 & 63.6 \\
\hline 2 & 0.86 & 0.22 & 4.15 & 0.48 & 0.25 & 5.98 & 47.6 \\
\hline 4 & 1.27 & 0.27 & 4.71 & 0.65 & 0.53 & 4.97 & 49.4 \\
\hline
\end{tabular}




\section{The following are a summary of significant results and findings from this task:}

- $\mathrm{CrCl}_{2}-\mathrm{CrCl}_{2} /[\mathrm{EMIN}] \mathrm{Cl}$ is still the most active catalyst system for cellulose conversion.

- HMF, sugar, and "unknown" are the major products produced from this ionic liquid catalytic process

- Nearly complete cellulose conversion (or decomposition) can occur with about 40-50 wt $\%$ of HMF yield. This looks very interesting. However, repeatability of this reaction process is poor.

- Complicated fundamental physical and chemical processes could be involved during the conversion, although performing reaction tests seems to be simple. There is a large gap in fundamental understandings to the ionic liquid catalysis.

- Mixing and heat transfer are two main problems to obtain a homogenous mixture and uniform temperature profiles. The ball-milling and extruding mixing may be an attractive mixing and reaction means.

\subsection{Task 4 - Technical and economic analysis for scale-up \\ Process flow diagram. The process scheme as illustrated in Figure 14 is conceived based} on the research results obtained from this project. Sugar is mixed with the ionic liquid and fed into a reactor by a twin screw extruder. The reactor (R-1) is operated as a continuous flow reactor. The reactor may be stirred mechanically or lifted by using a purge gas. The purge gas carries water vapor produced from the dehydration reaction away from the reactor. The water vapor in the purge gas is condensed into liquid water that can be used for the adsorption column flushing. The reacted mixture is withdrawn from the bottom of the reactor and is quenched by mixing a cold water stream. The mixture goes through a static mixer. The particulate in the mixed process stream 9 is filtered out as a waste. The particulate may be formed due to side reactions in the reactor, such as charring. The clear solution is fed into the adsorption column (A1). Two adsorption beds are used in the process. One is used for the adsorption, while another one is being regenerated. HMF product is adsorbed inside the bed. The effluent - stream 11 is sent to a drier (D-1), where water in the stream 11 is removed by vacuum vaporization. The water is recovered for re-use. The de-watered ionic liquid -stream 13 is recycled. A small fraction of the recycled ionic stream 13 may be bypassed into a heater, where refractory compounds such as glucose can be charred into particulates and removed by a filter. In this way, 
the refractory compounds would not accumulate in the recycle loop. Some acids may exist in the distilled water stream 18, which can be separated out by using an adsorbent bed (A-3) to avoid their accumulation inside the reaction loop.

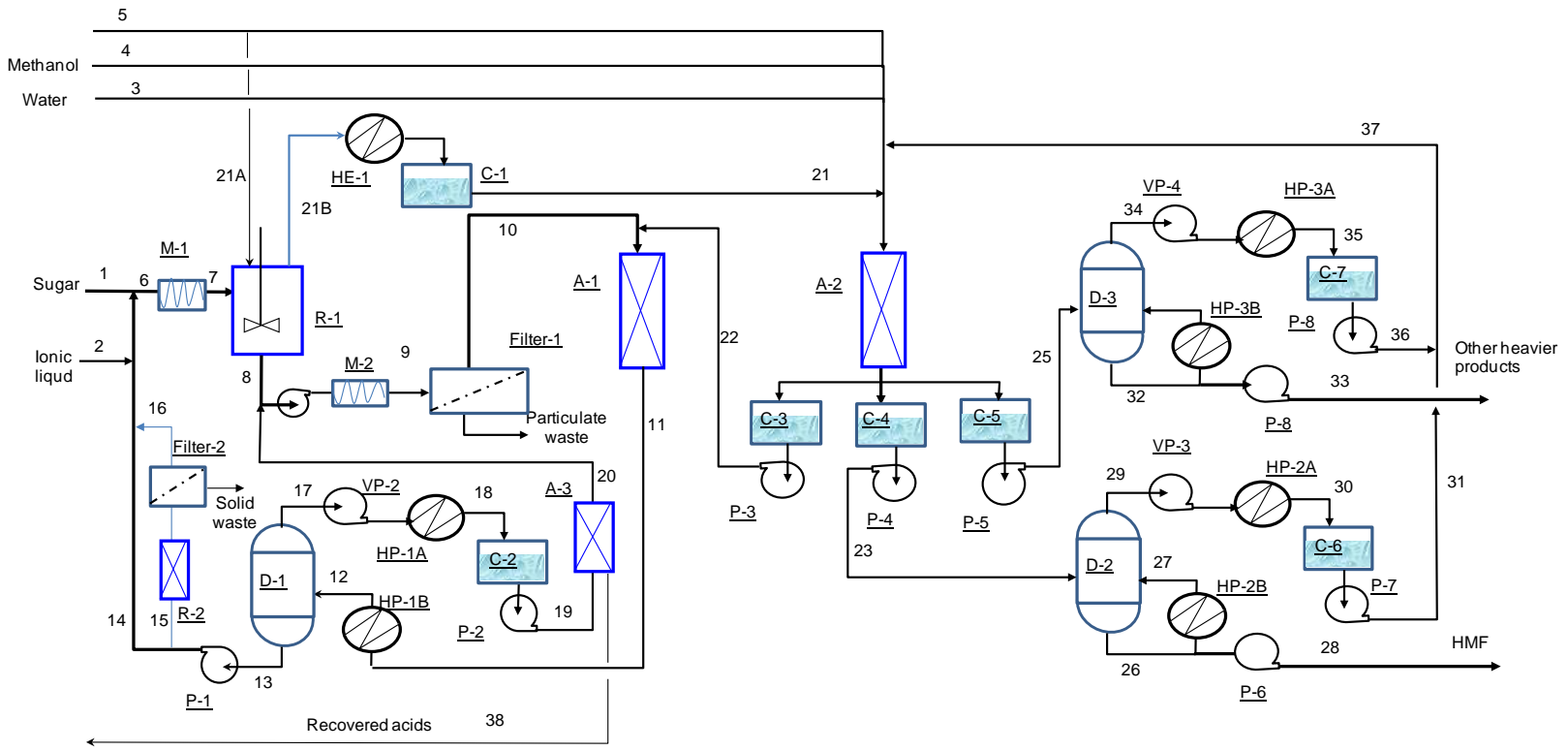

Figure 14. Process flow diagram for an ionic liquid catalytic process for conversion of fructose into HMF.

The saturated adsorption bed is first purged with an inert gas. The adsorption feed, which is trapped in the pipeline and inter-particle voids of the adsorption bed, is collected in a container C-3. Then, the saturated bed is flushed with process water to get the trapped ionic liquid residual be completely purged out of the adsorption bed without causing HMF desorption. The water purge fluid is also collected in vessel C-3. The collected ionic liquid mixture in C-3 is sent back to the adsorption column. After the water flushing, methanol is introduced into the bed to generate the saturated adsorbent. The methanol effluent in early stage, which contains concentrated HMF, is collected in a vessel C-4. The HMF concentrate is pumped into a fractionation town D-2, where methanol solvent is vaporized and recovered, and pure HMF product is produced. The tail portion of the methanol effluent is collected in the vessel C-5. After the methanol flushing, the bed is purged with the inert gas. The methanol purged out by the gas is collected in the vessel C-5. The fluid collected in C-5 mostly consists of methanol and maybe 
small amounts of byproducts. The byproduct may be separated through a distillation column D3.

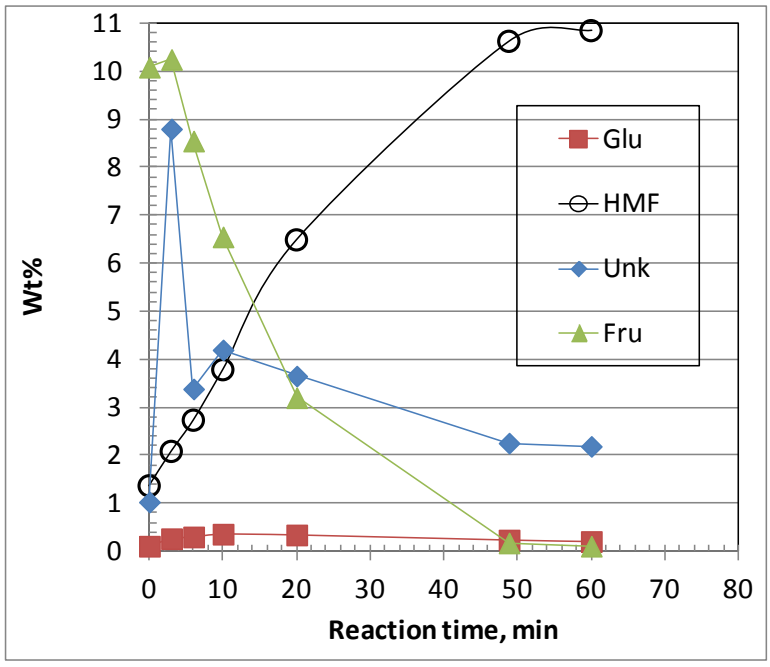

(a). Reaction temperature of $110^{\circ} \mathrm{C}$

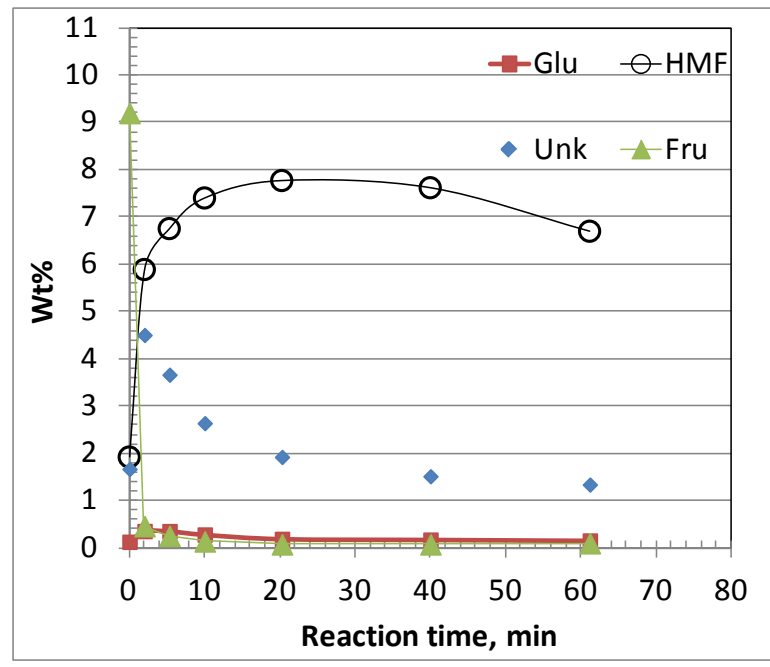

(b). Reaction temperature of $130^{\circ} \mathrm{C}$

Figure 15. Conversion of fructose and unknown with recycled ionic liquid.

Use of recycled ionic liquid and conversion of unknown. The presence of unknown in the reacted mixture was identified in the above reaction process study. The unknown and unconverted sugar eluted out of the adsorbent bed together with the ionic liquid. For a continuous production process, unknown should not accumulate in the recycle loop. To verify this, we conducted fructose conversion tests with the recycled ionic liquid. Figures 15a and 15b show the conversion profiles at two different reaction temperatures, respectively. For the run in Figure 15a, the recycled ionic liquid contained $1.49 \%$ unknown, $0.11 \%$ glucose, and $0.26 \%$ fructose, and $9.0 \%$ of fresh fructose feed was added into the ionic liquid. The unknown and fructose content showed a spike initially and then decline with time, while HMF content increased monotonically. The recycled ionic liquid used for the run shown in Figure 15b contained 2.59\% unknown, $0.24 \%$ glucose, and $0.26 \%$ fructose. $9.1 \%$ fresh fructose feed was added into this ionic liquid. At a higher temperature $\left(130^{\circ} \mathrm{C}\right)$, HMF production, and fructose and unknown conversion appeared much faster than those at $110^{\circ} \mathrm{C}$. These tests confirmed that the recycled ionic liquid is effective for conversion of fructose and unknown, and the accumulation of unknown inside the recycle loop can be controlled by adjusting reaction conditions. The carbon 
balance shows that conversion of fructose to HMF is almost stoichiometric by using the recycled ionic liquid.

Sizing of key equipment. The sizes of reactor and adsorbent bed volumes are estimated based on the reaction and adsorption kinetics at a capacity scale of 200, 000 ton/year of fructose feedstock. HMF yield is assumed to be $98 \%$ on the molar basis. Major process design parameters are listed in Table 12. The reactor and adsorbent bed sizes are about 200 and $120 \mathrm{m3}$, respectively, which are typical for an industrial plant. The HMF output would be 137,200 ton/year. The mass difference from fructose feedstock is due to water loss.

Table 12. Sizes of main equipment for proposed process flow diagram.

\begin{tabular}{|l|r|}
\hline Fructose feed, T/year & 200,000 \\
\hline Plant service time, hour/year & 8,000 \\
\hline Reactor 1 & \\
\hline Temperature, ${ }^{\circ} \mathrm{C}$ & 110 \\
\hline Pressure, bar & 1.2 \\
\hline Residence time, min & 20 \\
\hline Gas or void fraction in reactor & 0.6 \\
\hline Reactor volume, ${ }^{3}$ & 198.4 \\
\hline HMF yield, mol/mol & 0.98 \\
\hline Adsorbent bed sizing - A2 & \\
\hline Adsorption temperature, ${ }^{\circ} \mathrm{C}$ & 50 \\
\hline Adsorbent bed pressure drop, bar & 2.0 \\
\hline Adsorption capacity of HMF, $\mathrm{wt} \%$ & $12.0 \%$ \\
\hline Adsorption breakthrough time, $\mathrm{h}$ & 1 \\
\hline amount of adsorbent, $\mathrm{T}$ & 119.6 \\
\hline Adsorbent bed packing density, T/m ${ }^{3}$ & 1 \\
\hline Volume of adsorbent bed, $\mathrm{m}^{3}$ & 119.6 \\
\hline HMF production - stream 28 & 17.15 \\
\hline mass flow rate, T/h & 137,200 \\
\hline mass flow rate, T/year & \\
\hline
\end{tabular}




\subsection{Conclusion}

- A low-cost ionic liquid (Cyphos 106) is discovered for conversion of fructose into HMF under moderate reaction conditions without any catalyst, 60 to $120^{\circ} \mathrm{C}, 5$ to $60 \mathrm{~min}$. $\mathrm{HMF}$ yield is almost $100 \%$ on the carbon molar basis. This appears to be a relatively simple reaction process.

- Adsorbent materials and adsorption process have been invented and demonstrated for separation of 99\% pure HMF product from the ionic liquid reaction mixtures. The adsorbent material appears very stable in repeated adsorption/regeneration cycles.

- Novel membrane-coated adsorbent particles are made and demonstrated to achieve excellent adsorption separation performances at low pressure drops. This is very important for a practical adsorption process because ionic liquids are known of high viscosity.

- Nearly $100 \%$ conversion (or dissolution) of cellulose in the catalytic ionic liquid into small molecules was observed. It is promising to produce HMF, sugars and other fermentable species directly from cellulose feedstock.

\section{Gap:}

- Reaction and separation tests at larger scales are needed to minimize impacts of incidental errors on the mass balance and to show $99.9 \%$ ionic liquid recovery

- The cellulose reaction tests were troubled with poor reproducibility. There are clear fundamental gaps for development of cellulose conversion process, which includes elucidation of reaction products, dissolution kinetics, mixing and heating effects, and separation of final reacting mixtures. 


\subsection{Intellectual Property and Documentation}

\section{Invention disclosure and patent application:}

1. W. Liu "Engineered particle with a molecular sieve membrane" Battelle Subject Invention No. 17089-E (provisional patent application filed on June 2nd, 2011).

2. W. Liu, H. Brown. "Ionic liquid for biomass conversion to petrochemical intermediate" Battelle Subject Invention No. 16310-E.

\section{Presentation:}

1. W. Liu "A Novel Ionic Liquid Process for Conversion of Renewable Biomass into Petrochemical Intermediate” presentation at the 13th Annual Green Chemistry \& Engineering Conference, College Park, MD, June 25th, 2009.

2. W. Liu, Allan Cooper, Richard Zheng, and Heather Brown. “An Ionic Liquid-based Process for Conversion of Biomass into 5-hydroxymethylfurfural (HMF) as Petrochemical Intermediate” Presentation at the AIChE Annual Meeting, Nashville, TX, Nov. 12, 2009

3. W. Liu, R. Zheng, J. Li, and A. Cooper “Adsorption Separation of Reaction Product From Ionic Liquid Reaction Mixture for Conversion of Biomass Into 5Hydroxymethylfurfural (HMF)" oral presentation accepted for AIChE Annual Meeting, Salt Lake City, Utah, Nov. 9th, 2010.

\section{Journal manuscript:}

- W. Liu, A. Cooper, H. Brown, R. Zheng, and J. Holladay “Catalytic Conversion of Sugar into 5-hydroxymethylfurfural in Ionic Liquids” manuscript prepared for Catalysis Today 2012.

- W. Liu, H. Brown, R. Zheng, J. Li, and A. Cooper "Adsorbents for Separation of furfural or aromatic-type Products from Ionic Liquid/water Reaction Mixtures” manuscript prepared for Ind. Eng. Chem. Res 2012.

- W. Liu, R. Zheng, J. Li, and A. Cooper "An Ionic Liquid Catalytic and Adsorption Separation Process for Production of HMF from Sugar” manuscript prepared for Energy and Environmental Science 2012. 


\subsection{Cited References}

M. Bicker, J. Hirth, H. Vogel, Green Chem. 5, 280 (2003).

Y. Fukaya, A. Sugimoto, H. Ohno, Biomacromolecules 7, 3295 (2006).

G.J.M. Gruter, F. Dautzenberg. European Patent 1834951 (publication date: Sep. 19, 2007).

G.W. Huber, J.N. Chheda, C.J. Barrett, J.A. Dumesic, Science 308, 1446 (2005).

G.W. Huber, S. Iborra, and A. Corma. Synthesis of transportation fuels from biomass: chemistry, catalysts, and engineering, Chem. Rev. 2006, 106,4044-4098

M. Kunz. "Hydroxymethylfurfural, a possible basic chemical for industry intermediates" in A. Fuchs (ed.) Inulin and Inulin-containing Crops, 1993 Elsevier Science Publishers B.V.

J. Lewkowski, ARKIVOC , 2001, (i) 17 (2001).

W. Liu, J.E. Holladay, R.Zheng, H. Brown, and A. Cooper “Adsorption Separation Processes for Ionic Liquid Catalytic Processes” US patent application US2011/0105770 A1 (May 5, 2011).

C. Moreau, A. Finiels, L. Vanoye, J. Mol. Catalysis A: Chemical 253, 165, (2006).

Y. Roman-Leshkov, J.N. Chheda, and J.A. Dumesic, Science 312, 1933-1937 (2006).

Su et al. Appl. Catal. A: General 361 (2009)117.

T. Werpy, G. Petersen. “Top value added chemicals from biomass”, Technical Report No. DOE/GO-102004-1992 (National Renewable Energy Lab, Golden, CO, 2004)

H. Zhao, J. E. Holladay, H. Brown, Z. C. Zhang, Science, 316, 1597 (2007). 

Distr.1 


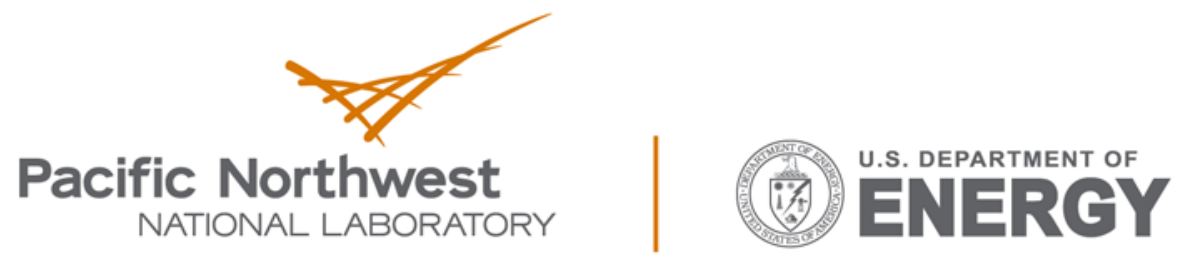

Proudly Operated by Battelle Since 1965

902 Battelle Boulevard

P.O. Box 999

Richland, WA 99352

1-888-375-PNNL (7665)

www.pnnl.gov 